NBER WORKING PAPER SERIES

\title{
THE WELFARE EFFECTS OF PEER ENTRY IN THE ACCOMMODATION MARKET: THE CASE OF AIRBNB
}

\author{
Chiara Farronato \\ Andrey Fradkin \\ Working Paper 24361 \\ http://www.nber.org/papers/w24361 \\ NATIONAL BUREAU OF ECONOMIC RESEARCH \\ 1050 Massachusetts Avenue \\ Cambridge, MA 02138 \\ February 2018
}

Katie Marlowe and Max Yixuan provided outstanding research assistance. We thank Nikhil Agarwal, Susan Athey, Matt Backus, Liran Einav, Christopher Knittel, Jonathan Levin, Greg Lewis, Chris Nosko, Debi Mohapatra, Ariel Pakes, Paulo Somaini, Sonny Tambe, Dan Waldinger, Ken Wilbur, Kevin Williams, Georgios Zervas, and numerous seminar participants for feedback. We are indebted to Airbnb's employees, in particular Peter Coles, Mike Egesdal, Riley Newman, and Igor Popov, for sharing data and insights. We also thank Duane Vinson at STR and Sergey Shebalov at Sabre for sharing valuable data insights. Airbnb reviewed the paper to make sure that required confidential information was reported accurately. STR reviewed the paper to verify that all data and information provided by STR and the STR SHARE Center were correctly cited. Farronato has no material financial relationship with entities related to this research. Fradkin was previously an employee of Airbnb, Inc. and holds stock that may constitute a material financial position. The views expressed are those of the authors and do not necessarily reflect the views of the National Bureau of Economic Research.

NBER working papers are circulated for discussion and comment purposes. They have not been peer-reviewed or been subject to the review by the NBER Board of Directors that accompanies official NBER publications.

(C) 2018 by Chiara Farronato and Andrey Fradkin. All rights reserved. Short sections of text, not to exceed two paragraphs, may be quoted without explicit permission provided that full credit, including $\odot$ notice, is given to the source. 
The Welfare Effects of Peer Entry in the Accommodation Market: The Case of Airbnb

Chiara Farronato and Andrey Fradkin

NBER Working Paper No. 24361

February 2018

JEL No. D4,D6,L1,L22,L23,L85,L86

\begin{abstract}
$\underline{\text { ABSTRACT }}$
We study the effects of enabling peer supply through Airbnb in the accommodation industry. We present a model of competition between flexible and dedicated sellers - peer hosts and hotels who provide differentiated products. We estimate this model using data from major US cities and quantify the welfare effects of Airbnb on travelers, hosts, and hotels. The welfare gains are concentrated in locations (New York) and times (New Years Eve) when hotels are capacity constrained. This occurs because peer hosts are responsive to market conditions, expand supply as hotels fill up, and keep hotel prices down as a result.
\end{abstract}

\author{
Chiara Farronato \\ Harvard Business School \\ Morgan Hall 427 \\ Soldiers Field \\ Boston, MA 02163 \\ and NBER \\ cfarronato@hbs.edu \\ Andrey Fradkin \\ MIT Sloan School of Management \\ E62 Room 412 \\ 30 Memorial Dr. \\ Cambridge, MA 02142 \\ afradkin@gmail.com
}

A data appendix is available at http://www.nber.org/data-appendix/w24361 


\section{Introduction}

The Internet has greatly reduced entry and advertising costs across a variety of industries. As an example, peer-to-peer marketplaces such as Airbnb, Uber, and Etsy currently provide a platform for small and part-time peer providers to sell their goods and services. Several of these marketplaces have grown quickly and become widely known brands. In this paper, we study the determinants and effects of peer production in the market for short-term accommodation, where Airbnb is the main peer-to-peer platform and hotels are incumbent suppliers.

We present a theoretical model of competition between incumbent hotels and peer hosts. We then use data from top US cities to test the model hypotheses about the entry of peer supply, and to quantify the effects of this entry on travelers, incumbent hotels, and peer hosts. We find that Airbnb generated $\$ 41$ of consumer surplus per room-night and $\$ 26$ of host surplus while reducing variable hotel profits from accommodations by up to $3.7 \%$. This resulted in a total welfare gain of $\$ 137$ million in 2014 from Airbnb in these cities and this effect was concentrated in locations (New York) and times (New Years Eve) where hotel capacity was constrained.

Since its founding in 2008, Airbnb has grown to list more rooms than any hotel group in the world. Yet Airbnb's growth across cities and over time has been highly heterogeneous, with supply shares ranging from over $15 \%$ to less than $1 \%$ across major US cities at the end of 2014. Airbnb's entry has also prompted policy discussion and varied regulation in many cities across the world. In order to understand Airbnb's growth and its effects, we propose a simple demand and supply framework where accommodations can be provided by either dedicated or flexible supply - hotels vs peer hosts.

The role of Airbnb in our framework is to lower entry costs for peer hosts. This reduction in entry costs is similar across cities but the benefits of hosting travelers vary. Prices and occupancy rates, as well as marginal costs affect the benefits of hosting travelers. In the long run, our model predicts higher entry of peer supply in cities with higher prices and occupancy rates, and lower peers' marginal costs. Prices and occupancy rates are in turn determined by the trend and variability in the number of travelers, as well as geographic and bureaucratic constraints to the expansion of hotel capacity. Marginal costs are determined by the perceived risk of hosting strangers, which is higher for families with children than for unmarried and childless adults. We confirm that these predictions hold in the 50 largest US cities in terms of hotel rooms. The entry of flexible supply is higher in cities like New York, where demand is growing and highly variable, where hotels are constrained from expanding room capacity, and where peer hosts have lower marginal costs than in cities like Atlanta. 
In the short-run, peer producers decide whether to host on a particular day. Because of the flexible nature of their supply, we hypothesize that these producers will be highly responsive to market conditions, hosting travelers when prices are high, and using accommodation for private use when prices are low. In contrast, because hotels have a fixed number of rooms dedicated to travelers' accommodation, they will typically choose to transact even when demand is relatively low, while they won't be able to expand capacity during peaks in demand. These differences imply that peer supply elasticity should be higher than hotels' supply elasticity on average. We validate this prediction by estimating a peer supply elasticity that is twice as high as hotels' elasticity.

The heterogeneous entry of peer hosts across cities and over time has surplus implications. We estimate our short-run equilibrium model to quantify the effect of Airbnb on total welfare and its distribution across travelers, peer hosts, and hotels. Travelers benefit from Airbnb for two reasons. First, flexible sellers offer a differentiated product relative to hotels. Second, they also compete with hotels by expanding the number of rooms available. This second effect is particularly important in periods of high demand when hotels are capacity constrained and can thus charge higher prices. Consequently, we find that the increase in consumer surplus from Airbnb is concentrated in city-days of peak demand, which the accommodation industry defines as compression nights. In those cities and periods, flexible sellers allow more travelers to stay in a city without greatly affecting the number of travelers staying at hotels.

Our data mainly come from two sources: proprietary data from Airbnb, and data from STR, which tracks supply and demand data for the hotel industry. We obtain data on average prices and rooms sold at a city, day, and accommodation type level between 2011 and 2014 for the 50 largest US cities. ${ }^{1}$ We first document heterogeneity in the number of Airbnb listings across cities and over time. Cities like New York and Los Angeles have grown more quickly, reaching supply shares exceeding $15 \%$ and $5 \%$ respectively in 2014, while cities like Oklahoma City and Memphis have grown more slowly, with less than 1\% supply shares at the of 2014. Within each city over time, the number of available rooms is higher during peak travel times such as Christmas and the summer. The geographic and time heterogeneity suggests that hosts flexibly choose when to list their rooms for rent on Airbnb, and are more likely to do so in cities and times when the returns to hosting are highest.

In Section 2, we incorporate this intuition into a model of the market for accommodations. In this model, rooms for accommodations can be provided by dedicated or flexible sellers, and products are differentiated. We include two time-horizons. The long-run horizon is characterized by the entry decision of flexible sellers given the new Airbnb platform. We model the decision of flexible sellers to join the platform as dependent on the expected

\footnotetext{
${ }^{1}$ The 50 largest US cities were selected on the basis of their total number of hotel rooms.
} 
returns from hosting, which in turn depend on competition from hotels and expected demand levels. The short-run horizon focuses on daily prices and quantities of rooms sold. We define the short-run horizon as one day in one city. In the short-run, the capacity of flexible and dedicated sellers is fixed, and overall demand level is realized. Travelers choose an accommodation option among differentiated hotel and Airbnb rooms. Hotels maximize profits subject to their capacity constraints, while peer hosts take prices as given.

The model offers testable predictions. The long-run share of flexible sellers should differ across cities. Entry should be largest in cities where hotel investment costs are high, flexible sellers' marginal costs are low, and demand variability is high so that there are periods of high prices. In the short-run, flexible sellers should increase competition: they will reduce prices and occupancy rates of hotels, and the effects will be largest in cities where hotel capacity is low relative to demand. We describe those cities as having constrained hotel capacity. In capacity-constrained cities, the model predicts that Airbnb reduces prices more than occupancy rates relative to non-capacity-constrained cities.

In Section 3, we confirm that these model predictions hold in the data. We first look at the long-run patterns. We show that peer supply as a share of total supply is larger in cities where hotel prices are higher. These high prices are associated with the difficulty of building hotels due to regulatory or geographic constraints. Peer supply is also larger in cities where residents tend to be single and have no children. These residents likely have lower costs of hosting strangers in their homes. Another factor influencing peer supply is the volatility of demand. A city can experience periods of high and low demand due to seasonality, festivals, or sporting events. When the difference in peaks and troughs is large, the provision of accommodation exclusively by hotels can be inefficiently low. We show that Airbnb's supply share is larger precisely in cities with high demand volatility, and, perhaps more intuitively, in cities where demand growth is high.

We then test the predictions of the model on short-run hotel outcomes. We do this by estimating regressions of hotel performance on Airbnb supply using two types of instruments as well as controls for aggregate demand shocks. We find that the negative effect of Airbnb on hotel revenues is larger in cities with constrained hotel capacity, and that compared to other cities, hotels here experience a bigger reduction in prices than occupancy rates. The heterogeneity in estimates is due to differences in both the size of Airbnb and the effects of Airbnb across markets conditional on that size.

In Section 4, we describe our estimation strategy for recovering the primitives of our model. We proceed in three steps. First, we estimate a random coefficient multinomial logit demand model (Berry et al. (1995)). We augment our estimation with survey data regarding the preferred second choices of Airbnb travelers, which helps us identify substitu- 
tion between Airbnb and hotel options. Second, we estimate hotels' cost functions assuming Cournot competition between hotels of the same scale. In order to take into account the fact that prices steeply increase when occupancy approaches 100\%, we follow Ryan (2012) and rationalize these price changes with marginal costs that start increasing when hotels are close to their capacity constraint. Third, we estimate the cost distribution of peer hosts assuming that they are price takers. Together, these estimates allow us to measure consumer and peer producer surplus, as well as to quantify how surplus would change in the absence of peer supply.

Section 5 presents our results for the top 10 US cities. We find that consumers' utility for Airbnb is lower than for hotels, but that preferences for Airbnb increase between 2013 and 2014. By the end of the sample period, the mean utility from top quality Airbnb listings is close to the mean utility of economy and midscale hotels. We find that peer hosts have higher marginal costs than hotels on average, and that consistent with our model, the distribution of peer costs makes peer supply highly elastic.

In the absence of Airbnb, total welfare would be lower, travelers and peer producers would be worse off, while hotels would benefit from less competition. In the top 10 US cities, total welfare would decrease by $\$ 137$ million and consumer surplus would decrease by $\$ 276$ million if Airbnb did not exist in 2014.

This corresponds to a consumer surplus of $\$ 41$ per night for every Airbnb booking. The reduction in consumer surplus if Airbnb did not exist occurs because fewer travelers would book rooms, and travelers who end up booking hotel rooms would pay higher prices. As it turns out, because of the elastic peer supply, actual Airbnb bookings and thus surplus gains disproportionately occur in cities (New York) and times (New Year's Eve) when hotel capacity constraints bind. This implies that in the absence of peer supply, travelers could not easily find a substitute hotel room because hotels would be fully booked. Indeed, we find that around half of Airbnb bookings would not have been hotel stays had Airbnb not existed.

The concentration of Airbnb bookings in cities and periods of peak demand suggests that in the absence of Airbnb, hotels would be limited in their ability to increase the number of booked rooms - they were already operating at or close to full capacity - but instead would be able to increase prices. Revenues for hotels would increase by $1.54 \%$ if Airbnb did not exist, and profits would likely increase by a larger percent. In fact, our estimates suggest that the variable profits of hotels could increase by up to $3.69 \%$ across the 10 cities in our sample.

We contribute to the growing empirical literature on online peer-to-peer platforms. A limited number of papers have looked at the effect of online platforms on incumbents, in 
particular Zervas et al. (2015) for Airbnb, Seamans and Zhu (2014) and Kroft and Pope (2014) for Craigslist, and Aguiar and Waldfogel (2015) for Spotify. In this paper we not only estimate the effects on incumbent firms, but also on consumers and new producers. In addition, we highlight important dimensions of heterogeneity of the effects of Airbnb across cities and over time. A complementary paper to ours is Cohen et al. (2016), which uses discontinuities in Uber's surge pricing policy to estimate the consumer surplus from ride sharing. Both of our papers find that successful peer-to-peer platforms generate substantial consumer surplus. However, while Cohen et al. (2016) assume that incumbents do not change their behavior, we incorporate capacity constraints and allow for hotel prices to adjust in the absence of Airbnb. This is important for our setting because even travelers who book hotel rooms benefit from Airbnb through lower prices. Similarly to us, Lam and Liu (2017) estimate a model of competition between Uber, Lyft, and taxis using data from New York.

Another related stream of research studies the role of peer-to-peer markets in enabling rental markets for durable goods. Horton and Zeckhauser (2016) derive a theoretical equilibrium model for ownership and rental of durable goods, and make predictions on the existence and size of rental markets across different product categories. Fraiberger and Sundararajan (2015) calibrate a model of car usage and quantify the expected reduction in car ownership as a result of peer-to-peer rental markets.

Our paper is also complementary to existing studies of labor supply and market design on peer-to-peer platforms. We find that host supply is highly elastic on the margin. This is consistent with analysis of suppliers on Taskrabbit (Cullen and Farronato (2017)) and Uber (Hall et al. (2016), Chen and Sheldon (2015)). Other work on peer-to-peer markets has focused on the market design aspects of reputation systems (Fradkin et al. (2017), Nosko and Tadelis (2015), Bolton et al. (2012)), search (Fradkin (2017), Horton (2016)), and pricing (Einav et al. (Forthcoming), Hall et al. (2016)). Specifically focused on the hotel industry, Lewis and Zervas (2016) study the welfare effects of online reviews. Finally, in our analysis of growth heterogeneity across cities, we contribute to the predominantly theoretical literature on technology adoption and diffusion (e.g. Bass (1969) and Griliches (1957)).

The paper is structured as follows. In the next section, we present the data and document geographic and time heterogeneity in the size of Airbnb, which motivates our theoretical framework of competition between dedicated and flexible sellers (Section 2.1). In Section 3 we test the predictions of our model on the long- and short-run elasticities of flexible supply, and on the competitive effects of Airbnb on hotels. Section 4 presents our empirical strategy for structurally estimating the short-run equilibrium of our model. We discuss the estimation results in Section 5 and conclude in Section 6. 


\section{Motivation and Theoretical Framework}

Airbnb describes itself as a trusted community marketplace for people to list, discover, and book unique accommodations around the world — online or from a mobile phone. The marketplace was founded in 2008 and has at least doubled in total transaction volume during every subsequent year in our sample. Airbnb has created a market for a previously rare transaction: the short-term rental of an apartment or room to strangers. In the past, these transactions were not commonly handled by single individuals because there were large costs to finding a match, securely exchanging money, and ensuring safety. While Airbnb is not the only company serving this market, it is the dominant platform in most US cities. ${ }^{2}$ Therefore, we use Airbnb data to study the drivers and the effects of facilitating peer entry in the accommodation market.

Airbnb room supply has grown quickly in the aggregate, but the growth has been highly heterogeneous across geographies. Figure 1 plots the size of Airbnb measured as the daily share of available Airbnb listings out of all rooms available for short-term accommodation. ${ }^{3}$ Even among the top 10 cities in terms of listings, there are high growth markets like San Francisco and New York, as well as slow growth markets like Chicago and DC. This increase in available rooms is specific to the peer-to-peer sector and does not represent a broader growth of the supply of short-term accommodation (see Figure A1).

Within a city over time, there is also heterogeneity in the size of Airbnb relative to the size of the hotel sector. The fluctuations are especially prominent in New York in Figure 1, which experiences large spikes in available rooms during New Year's Eve, and in Austin during the South by Southwest festival. The figure suggests that market conditions during these spikes are especially suited to peer-to-peer transactions. These facts motivate our theoretical model, in which we distinguish between dedicated sellers (hotels) and flexible sellers (peer hosts).

\subsection{Theoretical Framework}

In this section, we introduce a theoretical model for understanding market structure with dedicated supply (hotels) and flexible supply (peer hosts) in the accommodation industry. We will test the predictions of this model in Section 3, and structurally estimate the short-run

\footnotetext{
${ }^{2}$ The most prominent competitor is Homeaway/VRBO, a subsidiary of Expedia. Its business has historically been concentrated in rentals of entire homes in vacation destinations, such as beach and skiing resorts.

${ }^{3}$ The total number of available rooms is the sum of available hotel rooms and listings available on Airbnb. The same heterogeneity is apparent if we adjust for capacity, or if we divide the number of Airbnb listings by the number of total housing units within an MSA.
} 
component in Section 4.

In our model, hosting services can be provided by dedicated and flexible sellers, who offer differentiated products. The model has a short and long-run component. The shortrun equilibrium consists of daily prices and rooms sold of each accommodation type as a function of the overall demand level and the respective capacities of dedicated and flexible suppliers. We assume hotels are competing against a fringe of flexible sellers. The longrun component determines the entry condition of flexible sellers as a function of fixed hotel capacity and the distribution of demand states.

We start with the short-run equilibrium representing daily market outcomes. We simplify the exposition by assuming that there is one single hotel and one undifferentiated type of Airbnb listings. In the empirical counterpart of this model in Section 4 we relax this assumption. Let $K_{h}$ denote the mass of existing dedicated capacity (number of hotel rooms), and $K_{a}$ the existing flexible capacity (Airbnb rooms). Demand state, $d$, is drawn from a distribution $F$, which can be interpreted as the distribution of demand states over the course of a year. Hotel rooms and Airbnb rooms are differentiated products. $Q_{i}^{d}\left(p_{i}, p_{j}\right)$ is the residual demand for product $i$ as a function of its price and the price of the other product. $Q_{i}^{d}\left(p_{i}, p_{j}\right)$ is assumed to be increasing in $d$ and $p_{j}$, and decreasing in its own price $p_{i}$.

The short-run sequence of events is as follows. Capacity $K_{h}$ and $K_{a}$ are given, demand state $d$ is realized, the hotel sets prices and at the same time Airbnb sellers choose whether to host at the prevailing prices. We assume that the hotel faces marginal cost $c_{h}$ to book one room for one night, and it sets its price to maximize profits subject to its capacity constraint:

$$
\begin{array}{cc}
\underset{p_{h}}{\operatorname{Max}} & Q_{h}^{d}\left(p_{h}, p_{a}\right)\left(p_{h}-c_{h}\right) \\
\text { s.t. } & Q_{h}^{d}\left(p_{h}, p_{a}\right) \leq K_{h}
\end{array}
$$

Flexible sellers have unit capacity and variable marginal costs of renting their room. We assume that marginal costs of peers are randomly drawn from a known distribution.

When choosing whether to rent out their room for a night, flexible producers take prices as given, and sell their unit if and only if the market clearing price is greater than their cost. The choices of individual hosts are aggregated to determine the total number of flexible rooms rented:

$$
Q_{a}^{d}\left(p_{a}, p_{h}\right)=K_{a} \operatorname{Pr}\left(c \leq p_{a}\right)
$$

where $K_{a}$ is the mass of peer hosts, and $\operatorname{Pr}\left(c \leq p_{a}\right)$ is the share of hosts with costs lower than $p_{a}$.

The market equilibrium consists of prices and quantities for hotel rooms and peer rooms $\left(p_{h}, p_{a}, q_{h}, q_{a}\right)$ that equate flexible and dedicated room demand with flexible and dedicated 
supply.

The short-run model already offers some comparative statics predictions, listed below and proven in Appendix A. Under standard conditions, hotel profits per available room, as well as both prices and occupancy rates, are lower if $K_{a}$ is higher. The separate effect of an increase in $K_{a}$ on hotel prices is higher if hotel capacity constraints are more often binding, but the opposite is true for the effect on occupancy. Intuitively, this occurs because the increase in flexible capacity affects hotels through a reduction in their residual demand (Figure 2), and when hotels are capacity constrained, their supply curve is vertical (Figure 2b). A marginal downward shift in residual demand will have no effect on quantity and a large effect on price if supply is perfectly inelastic.

In the long-run, entry of flexible suppliers is endogenous. We assume that $K_{h}$ was optimally set knowing the distribution of demand states and not expecting that Airbnb would lower entry costs of flexible sellers. Holding demand fixed, if investing in hotel capacity is more costly, optimal dedicated capacity is lower and expected profits per unit of capacity are higher.

A peer-to-peer platform enables the entry of flexible sellers. Flexible sellers decide whether to join the peer-to-peer platform and start producing as a function of expected demand and expected marginal costs. We assume that flexible sellers face a one-time cost $C$ of joining the platform, which is randomly drawn from a given distribution. We let $v_{a}=\int_{d} E_{c}\left(\max \left\{0, p_{a}^{d}-c\right\}\right) d F(d)$ be the expected daily benefit of joining the platform. The expression $E_{c}\left(\max \left\{0, p_{a}^{d}-c\right\}\right)$ denotes the expected profit of a flexible seller given demand state $d$, where the expectation is taken over the distribution of marginal costs.

A flexible seller joins the peer-to-peer platform if the expected benefits are higher than the entry cost. If expected daily profits $v_{a}$ are higher, more flexible sellers will join the platform and start producing, and the share of flexible supply out of total supply will be higher. What affects $v_{a}$ ? The first element is the distribution of marginal costs $c$. Holding everything else constant, if the distribution of costs decreases in the sense of first order stochastic dominance, more peers will enter and start hosting. The second element is $p_{a}^{d}$, itself a function of $K_{h}$ and the distribution of demand $F(d)$. All else equal, a lower $K_{h}$ will increase equilibrium prices whenever capacity constraints bind, so it will increase the distribution of $p_{a}^{d}$ in the first order stochastic dominance sense. Clearly, a higher level of demand in every state is more attractive, but, perhaps less obviously, also an increase in demand variability is attractive for flexible suppliers. To explain why, we can think of a simple mean-preserving spread of two demand states. In the low demand state, flexible suppliers host very few travelers in either case because hotels are not capacity constrained, leading to low equilibrium prices. The difference occurs in high demand states. If the high demand state doubles, prices increase 
steeply, especially if hotel capacity constraints are hit, making it very attractive for flexible suppliers to host in periods of high demand. Appendix A formally states the assumptions and proofs for these results. Section 3.2 confirms that these comparative statics predictions hold in the data.

Before presenting our data, we should note that our model does not allow hotels to adjust dedicated capacity $K_{h}$ in response to peer entry. In the long-run, peer entry could partially crowd out dedicated sellers. Since our data only spans the first few years of Airbnb diffusion and hotel construction projects take between 3 and 5 years to complete, we are unable to empirically capture hotels' capacity adjustments. Exploring the entry and exit decisions of dedicated producers would be a valuable extension of our work.

\section{Data and Tests of the Model}

In this section, we describe our data on Airbnb and hotels and document how it confirms the predictions of the theoretical framework. Our proprietary Airbnb data consists of information aggregated at the level of listing types. The variables we observe include the number of bookings, active and available listings, as well as average listed and transacted prices. An available listing is defined as one that is either booked through Airbnb or is open to being booked on the date of stay according to a host's calendar. An active room is defined as a listing that is available to be booked or is already booked for at least one date in the future. Average transacted prices are calculated among all booked rooms on a given date, regardless of the time of booking. Analogously, average listed prices are calculated among all available rooms on the day of stay, regardless of prior price changes.

We categorize Airbnb listings into four types: 'Airbnb Luxury', 'Airbnb Upscale', 'Airbnb Midscale', and 'Airbnb Economy'. ${ }^{4}$ Listing types are defined using the following algorithm. We first run a city level hedonic regression of nightly price on listing fixed effects, date fixed effects, and bins for the number of five-star reviews. ${ }^{5}$ Second, we extract the listing fixed effects and use Bayesian shrinkage to shrink fixed effects towards the mean. Third, we compute quartiles of listing quality and categorize a listing in a given quartile if its fixed effect plus review coefficient falls into the appropriate range. This procedure allows us to account for heterogeneity in Airbnb listing types without specifically modeling detailed geographic and room type characteristics at a city level.

The hotel data come from STR, an accommodation industry data provider that tracks

\footnotetext{
${ }^{4}$ These categories are defined solely for the purpose of this paper and do not correspond to any metric used by Airbnb itself.

${ }^{5}$ The bins for the number of reviews are: $0,1,2-3,4-5,6-10,11-25,26-50,51-100, \geq 101$.
} 
over 161,000 hotels. Our sample contains daily prices and occupancy rates for the 50 largest US cities for the period between January 2011 and December 2014. ${ }^{6}$ STR obtains its information by running a periodic survey of hotels, to which they ask daily revenue attributable to the sale of hotel rooms, total rooms sold, and total rooms available. For the 50 largest markets, $68 \%$ of properties are surveyed, covering $81 \%$ of available rooms. STR uses supplementary data on similar hotels to impute outcomes for the remaining hotels which are in their census but do not participate in the survey. The data is then aggregated to six hotel scales, from luxury to economy, which indicate the quality and amenities of the hotels. So the data tell us, for example, the average price and the total number of rooms sold on January $10^{\text {th }}$, 2013, of midscale hotels in San Francisco.

Table 1 shows city-level descriptive statistics regarding hotels and Airbnb. In the average city, hotels charge $\$ 108$ per room and their occupancy rate is $66 \%$. Perhaps surprisingly, Airbnb has very similar transacted prices (\$109) and much lower occupancy rates (15\%). The within-city standard deviation of these outcomes varies greatly across cities. For example, the city at the 25 th percentile has a standard deviation of hotel prices of $\$ 10$ ( $\$ 22$ for Airbnb prices), while the city at the 75th percentile has a standard deviation of $\$ 21$ (\$34 for Airbnb prices). This indicates that markets differ not only in levels but in the extent to which conditions fluctuate within a year and over time.

During our sample period, Airbnb comprises a small share of the overall market as a percentage of total rooms available for short-term accommodation. The average Airbnb share of available rooms in the last quarter of 2014 is $2 \%$, and in most cities it is between $1 \%$ and $3 \%$ (25th and 75th percentiles). Two other normalizations confirm that Airbnb was still small in most US cities by the end of our sample period. Across all cities, Airbnb rooms represent $4 \%$ of all guests and represent less than $1 \%$ of total housing units for all metropolitan statistical areas (MSAs) in our sample.

\subsection{The Long-Run: Determinants of Peer Entry}

In this section, we verify the theoretical predictions regarding the long-run growth of peer supply from Section 2.1. Although the theoretical model assumes that entry decisions are made instantaneously and jointly for all flexible sellers, in practice awareness about the Airbnb platform has grown between 2011 and 2014. We assume that the last quarter in 2014, the end of our sample, provides a valid proxy for the long-run share of peer supply derived in our model.

\footnotetext{
${ }^{6}$ The cities are ranked based on the absolute number of hotel rooms in 2014. See Census Database: http: //www.str.com/products/census-database and STR Trend Reports: http://www.str.com/products/ trend-reports
} 
Figure 3 shows the relationship between Airbnb share of room capacity and hotel daily revenues per available room. Not surprisingly, the size of Airbnb is positively correlated with the average revenue per available room in a city, with New York being both the city with the highest hotel revenues and the one with the highest penetration of peer hosts.

Our theory predicts that if hotels have high investment costs or peer hosts have low marginal costs, profitability for peer hosts will be high. So we should expect more peer entry in cities with high hotels' fixed costs and low peers' marginal costs. We use two proxies for hotel fixed costs. The first is the share of undevelopable area constructed by Saiz (2010). The index measures the share of a metropolitan area that is undevelopable due to geographic constraints, e.g. bodies of water or steep mountains. The second index is the Wharton Residential Land Use Regulatory Index (WRLURI), which measures regulation related to land use in each metropolitan area and is based on a nationwide survey described in Gyourko et al. (2008). ${ }^{7}$ Figures 4a and A2 confirm that constraints to hotel capacity are correlated with the share of peer supply. ${ }^{8}$

The second cost factor influencing the viability of peer production is the marginal cost of peers. Although many factors affect the costs of hosting, we focus on those related to demographics. ${ }^{9}$ Households vary in their propensities to host strangers in their homes. For example, an unmarried 30-year-old professional will likely be more open to hosting strangers than a family with children. This occurs for at least two reasons. First, children increase a host's perceived risk of the transaction. Second, unmarried professionals are more likely to travel, creating vacant space to be rented on Airbnb. Figure $4 \mathrm{~b}$ plots the share of peer supply at the end of 2014 against the percentage of unmarried adults, while Figure A2 uses the percentage of children. The figures confirm that cities with more unmarried adults and fewer children are those where Airbnb represents a higher share of accommodation rooms.

In addition to cost factors, our model predicts that travelers' demand affects peer entry. This is due to two related reasons. First, hotels typically do not have enough dedicated capacity to absorb all potential travelers in times of peak demand. In contrast, flexible sellers are able to provide additional supply during peak times, when their rooms are especially valuable to travelers. Second, since hotels must pre-commit to capacity and any adjustment in the form of new hotel buildings takes 3 to 5 years, unforeseen growth in demand will

\footnotetext{
${ }^{7}$ Saiz (2010) uses these two measures to calculate the housing supply elasticity at the level of a metropolitan area.

${ }^{8}$ Building restrictions also affect Airbnb supply through another channel, the cost of residential housing. There are greater incentives to monetize a spare bedroom when the costs of housing are higher, especially for liquidity constrained households. Figure A2 in the Appendix confirms a positive relationship between the share of household income used to pay rent in 2010 and the size of Airbnb in 2014.

${ }^{9}$ Other potential shifters of the returns to hosting include household liquidity constraints, building regulation and enforcement of short-term rentals, and the ease of vacating an apartment in high demand periods.
} 
create an inefficiently low dedicated supply and will induce entry by flexible sellers.

We use data from air travelers to proxy for accommodation demand trends and fluctuations at the city-month level. We measure these demand characteristics in 2011, the earliest year in our sample, in order to reduce the risk that peer entry influences demand rather than vice versa. Our data come from Sabre Travel Solutions, the largest Global Distribution Systems provider for air bookings in the US. We isolate trips entering a city as part of a round trip from a different city in order to measure the potential demand for short-term stays. ${ }^{10}$ Figure 5a confirms the intuition that year-on-year demand growth results in greater peer entry by showing that the 2012-2011 growth rate in travelers to a city is positively related to Airbnb penetration in 2014. Figure 5b plots the standard deviation of demand in 2011 and confirms that by the end of 2014 Airbnb is bigger in cities where the fluctuations in the number of arriving travelers are larger.

To conclude this section, we combine all the descriptive results into a regression. Table 2 displays the summary statistics for the cost and demand factors described above. Table 3 displays results from a regression where the dependent variable is the size of Airbnb in the last quarter of 2014 and the explanatory variables are combinations of the measures of relative costs, demand growth, and demand variability described above. We also control for market size in order to isolate the component of the standard deviation of demand which is due to demand variability. Despite the small sample size, column (1) shows that all factors affect the size of Airbnb in the expected direction, and two coefficients are statistically significant - peers' marginal costs, and demand volatility. Column (2) adds additional and potentially redundant proxies for costs and demand. The coefficients are in the expected direction for all proxies.

In the last column of Table 3 we add the 2011 average revenue per hotel room as an additional control. The coefficient on revenue per available room is positive and statistically significant, while the coefficients on the demand and hotel investment cost proxies decrease in magnitude and become insignificant. This result suggests that demand proxies and hotel investment costs affect peer entry mostly through price and occupancy as expected. Taken altogether, our proxies for the determinants of long-run peer supply explain between $60 \%$ and $75 \%$ of the variation across our cross-section of US cities.

\subsection{The Short-Run: Effects of Peer Entry on Hotels}

In the previous section we have tested the long-run predictions of our theoretical model, those related to the entry of peer producers. Here, we take entry as given, and focus on the

\footnotetext{
${ }^{10}$ Data from Sabre include monthly number of passengers by origin and destination airport. We aggregate these observations to an MSA-month measure of air travelers.
} 
short-run drivers of peer supply to test our model hypotheses on the effects of peer supply on hotels. The awareness and diffusion process of Airbnb and its variation across cities help us test these hypotheses.

First, we show how to properly measure the size of Airbnb, and how the short-run elasticity of Airbnb supply is twice as large as that of hotels. Then, we use an instrumental variable approach to study the reduction in hotel revenues after the entry of Airbnb, and its heterogeneity across cities and hotel scales.

\section{Measuring Airbnb Supply}

We start by demonstrating how to properly measure Airbnb supply and studying how hosts flexibly respond to fluctuations in market-level demand over time. Figure 6 displays four measures of the size of Airbnb plotted over time: active listings, two measures of available listings, and booked listings. This figure displays three important facts. First, the share of active or available listings that are booked varies greatly over time. The booking rate is especially high during periods of high demand such as New Year's Eve and the summer. What we will show just below is that this is the result of a highly elastic peer supply. Second, the gap between active listings and available listings is increasing over time, suggesting attrition in active listings. Therefore, the meaning of an active listing does not stay constant over the entire period of study.

The third and most relevant fact from Figure 6 is that the number of unadjusted available listings (blue line) actually decreases during periods of high demand, most notably on New Year's Eve. The main reason for this is that calendar updating behavior responds to room demand. Many hosts do not pro-actively take the effort to block a date on their calendar when they are unavailable (see Fradkin (2017) for evidence). However, when they receive a request to book a room, they often reject the guest and update their calendar accordingly. Since a larger share of listings receives inquiries during high demand periods, the calendar is also more accurate during those times. Therefore, the naively calculated availability measure suffers from endogeneity and is even counter-cyclical - high when demand is low, and low otherwise.

Since we need a measure of the size of Airbnb that stays stable over time, we create an adjusted measure of available listings. This measure includes any rooms which were listed as available for a given date or were sent an inquiry for a given date and later became unavailable. Therefore, it does not suffer from the problem of demand-induced calendar updating. It does overstate the "true" number of available rooms in the market, but as long as it overestimates true availability consistently over time we consider it to be the best measure of Airbnb size. Figure 6 displays our proposed measure (red line) against the 
naive measure of available listings (blue line). The new measure does not suffer from drops in availability during high demand periods. Throughout the rest of the paper we use the adjusted number of available listings as the size of Airbnb supply unless otherwise noted.

\section{Peers' Responses to Demand Fluctuations}

From Figure 6 it is clear that Airbnb bookings fluctuate over time: more rooms are booked during the peak season than in other periods. In this section, we use 2SLS to document that flexible suppliers are almost twice as elastic as dedicated suppliers.

We estimate the average supply elasticity of hotel and Airbnb rooms with respect to their prices using the following equation:

$$
\log \left(Q_{m t}\right)=\chi \log \left(K_{m t}\right)+\kappa \log \left(p_{m t}\right)+\mu_{m t}+\epsilon_{m t}
$$

where $Q_{m t}$ is the number of (hotel or Airbnb) bookings in city $m$ and day $t, K$ denotes capacity, and $p$ is the average transacted price. The equation is estimated separately for hotels and Airbnb. $\kappa$ is the elasticity of supply with respect to prices, and will be different between flexible and dedicated supply. $\mu_{m t}$ includes city, seasonality (month-year), and day of week fixed effects to control for the fact that costs might change by city or over time (e.g., due to average differences in costs over cities or due to particular periods where hosts are less likely to occupy their residences).

Equation 3 suffers from standard simultaneity bias because the price of accommodations is correlated with demand, and with unobserved fluctuations in marginal costs. Furthermore, in the case of Airbnb, the number of available rooms $K_{m t}$ is itself endogenous because hosts may list their room as available precisely during high demand periods. ${ }^{11}$

We discuss each concern in order. We instrument for price with plausibly exogenous demand fluctuations which are typically caused by holidays or special events in a city. We use two instruments. The first is the number of arriving (not returning) flight travelers in a city-month, which we used in Section 3.1. The second comes from Google Trends, which provides a normalized measure of weekly search volume for a given query on Google. Our query of interest is "hotel(s) $c$ ", where $c$ is the name of a US city in our sample. We de-trend each city's Google Trends series using a common linear trend to remove long-run changes in overall search behavior on Google. We use the one-week lagged search volume as an instrument. Using other lags or the contemporaneous search volume yields similar estimates.

\footnotetext{
${ }^{11}$ The same endogeneity issue is not important for hotels because hotel capacity is typically fixed in a 4-year interval, our sample period. However, instrumenting for hotel capacity with a quadratic time trend, as we do for Airbnb, does not change our results.
} 
To control for the fact that room availability on Airbnb is endogenous to demand, we instrument for the number of available listings with a city-specific quadratic time trend. It is reasonable to believe that this instrument captures the long-run diffusion process of Airbnb while being uncorrelated with contemporaneous idiosyncratic shocks to supply. We use this same instrumentation strategy below to test for the effect of Airbnb supply on hotel revenues predicted by our model.

Table 4 contains our estimates of Equation 3 for Airbnb and hotels separately. Turning first to column 1, a $1 \%$ increase in the average hotel daily rate increases hotel bookings by $1.1 \%$. This elasticity is half as large as that of Airbnb (column 2), whose estimated elasticity is 2.2. An important implication of this result is that smaller fluctuations in prices are needed for Airbnb supply to adjust upward or downward.

We have shown that the Airbnb supply is highly responsive to price, more so than hotels: a small price increase due to high demand greatly increases the number of booked rooms on Airbnb, and this increase is twice as large as for hotels. The lower elasticity of hotel supply has a simple explanation. To the extent that hotels have a constant marginal cost and a fixed supply, hotel bookings cannot increase in response to increases in demand when demand is sufficiently high. The higher elasticity of flexible supply implies that there are many hosts willing to rent their rooms when prices are high, but prefer not to host when prices are just a little lower. Our structural model in Section 4 rationalizes this result by estimating that there is a large mass of peers with costs close to the market clearing prices.

\section{Effects of Peer Entry on Hotel Revenue}

In this section, we test our model hypotheses on the effects of peer entry on hotels' revenue, occupancy rates, and prices using linear specifications. Before describing our empirical strategy, we discuss the two most important challenges to identifying the effect of Airbnb. To do this, we consider the hypothetical scenario where Airbnb supply grows randomly across cities and over time. In this scenario, regressing the outcomes of hotels on the Airbnb supply would yield an unbiased estimate of the causal effect of Airbnb supply. However, as highlighted above, Airbnb supply does not grow randomly. In fact, Airbnb supply is larger in cities with high hotel revenues, and during periods of high demand within each city. Observables like the number of arriving flight travelers, city fixed effects, and seasonality fixed effects, help us control for this selection.

We instrument for the currently available Airbnb supply with a city-specific quadratic time trend, which isolates the predictable diffusion of Airbnb over-time from the endogenous short-run Airbnb supply responses to demand shocks during peak days such as holidays. The key assumption behind this identification strategy is that there are no other city-specific 
trends conditional on observables. ${ }^{12}$ We remove this assumption in our structural estimation in Section 5, which relies on plausibly exogenous components of price variation and market structure to identify the effects of interest.

Our baseline regression specification is:

$$
y_{m t}=\alpha \log \left(\text { airbnb }_{m t}\right)+\beta \log \left(\text { gtrend }_{m t}\right)+\gamma \log \left(\text { traveler } s_{m t}\right)+\theta_{m t}+\nu_{m t} .
$$

Here $y_{m t}$ is one of three hotel outcomes (log revenue per available room, log price, occupancy rate) in a city $m$ on day $t$, airbnb $b_{m t}$ is the number of available Airbnb listings, gtrend $_{m t}$ is the one-week lag of Google searches for hotels in the city, traveler $s_{m t}$ is the number of arriving air passengers, and $\theta_{m t}$ includes city, quarter-year, and day of week fixed effects. Importantly, the Google metric captures demand shocks at the week level, while the number of incoming air passengers captures monthly fluctuations in demand. The fixed effects capture seasonality, differences across the days of the week, and time-invariant city characteristics that affect both the size of Airbnb and hotel revenue.

The effect of interest is $\alpha$, which is the average short-run elasticity of hotel outcomes to peers' supply over our sample period. The coefficient is identified off of two types of variation. First, there is variation across cities and over time in the number of available listings due to increasing awareness of Airbnb. Second, there is variation in the availability of listings due to hosts' daily costs of hosting, which we assume are uncorrelated with residual daily demand for accommodation within the city.

Table 5 displays the results of the baseline specification. The coefficient on Airbnb size in column (1) is statistically significant and the estimated elasticity for hotel revenue is -.033. This coefficient implies that a $10 \%$ increase in available listings decreases the revenue per hotel room by $0.33 \%$. The coefficient estimates for our demand proxies, Google trends and arriving air travelers, are of the correct sign and statistically significant. Once we break down the effect into a reduction in occupancy rates (column 2) and a reduction in prices (column 3), we see that on average Airbnb has a larger effect on prices than on occupancy rates.

Recall that our model predicts that, holding fixed Airbnb supply, in days and cities when hotels are not capacity-constrained, Airbnb should have a relatively bigger effect on occupancy than on price. The opposite is true when hotels are capacity-constrained: on those days, Airbnb should have a relatively bigger effect on price than on occupancy. We also predicted and confirmed empirically that there will be more Airbnb rooms available in cities where hotels are often capacity constrained. Consequently, our theory predicts that

\footnotetext{
${ }^{12}$ In Appendix B we conduct robustness checks to demonstrate that these controls and instruments likely capture potential sources of endogeneity.
} 
we will find larger effects of Airbnb in constrained cities and that the price rather than occupancy channel will be more important in these cities than in non-constrained cities.

To test this prediction, we divide our cities into two groups and explore the heterogeneity of the effect of Airbnb across cities. Saiz (2010) uses the WRLURI and the share of undevelopable area described in Section 3.1 to estimate the housing supply elasticity at the city level. We take that supply elasticity as a proxy for the elasticity of hotel construction, and split our sample of cities at the median level of Saiz's estimates for the cities in our sample. Table 6 displays the estimates of Equation 4 separately for the two groups of cities. Columns (1) and (4) display the estimates of the effect on revenue per available hotel room. Both coefficients on Airbnb are statistically insignificant. When we break the outcomes into prices and occupancy rates, we see that the statistically significant effect of Airbnb is a reduction in hotel prices in the cities where hotels are capacity constrained (column 3). This is consistent with the fact that binding capacity constraints lead to spikes in hotel prices, which in turn attract more competition from Airbnb. When Airbnb enters, hotels are often fully booked, so they face more pressure on prices than on occupancy. Table A4 separates the effect in constrained cities by hotel scale and detects effects on all hotel scales other than Luxury.

Differences in the effect of Airbnb on hotels across constrained and unconstrained cities occur for two reasons. First, for the same level of Airbnb and hotel capacity, the effect of Airbnb is relatively larger on prices if hotel capacity constraints are more often binding (due to higher levels of demand). Second, for the same level of demand and hotel capacity, the effect on hotel revenues is larger if there are more Airbnb listings. Intuitively, the elasticity of hotel revenues with respect to the size of Airbnb should be higher, the higher the Airbnb share of supply because a 1 percent increase in Airbnb size is a much bigger share of market supply when Airbnb penetration is $3 \%$ then when it is $1 \%$. Both conditions are true when we split our cities. Indeed, in December 2014 the average Airbnb supply share in hotel-constrained cities was $4.3 \%$ while it was only in $1.4 \%$ in unconstrained cities. At the same time, the average hotel occupancy rate was $61 \%$ in constrained cities and only $53 \%$ in unconstrained cities.

Before concluding this section, one caveat is in order. In these specifications we cannot take advantage of exogenous changes in price that would allow for a valid causal estimate of the effect of Airbnb on hotel performance. For that analysis we refer the reader to Section 5. However, this exercise helped us confirm that the main predictions of our model from Section 2 hold in the data. We documented that the entry of peer hosts is responsive to long-run supply and demand characteristics. Peer supply is more likely to enter in cities where hotels' fixed costs are high, where peers marginal costs are low, and where demand is increasing and highly variable. We have also shown that flexible supply is highly elastic, 
and twice as elastic as dedicated supply. Finally, we have shown that the entry of flexible supply has negative spillovers on the revenue of dedicated suppliers. This negative effect is higher in cities with binding hotel capacity constraints and has a relatively larger impact on prices in those cities. In the rest of the paper, we structurally estimate our short-run model in order to measure the welfare effects of Airbnb on consumers, peer hosts, and hotels.

\section{Model and Estimation Strategy}

In this section, we describe the fully specified short-run model that we estimate. This extends the theoretical model from Section 2 to multiple hotel and Airbnb listing types. A market $n$ is defined by day $t$ and city $m$. On the demand side, our model is a random coefficients logit model (Petrin (2002) and Berry et al. (1995)), where rooms are differentiated across hotel scales and Airbnb listing types. On the supply side, we assume that hotels engage in Cournot competition with differentiated products across scales. Within a scale, each hotel is undifferentiated. Airbnb hosts are price takers with randomly drawn marginal costs.

\section{Consumer Demand}

Consumers make a discrete choice between hotel scales, Airbnb listing types, and an outside option for a given night. Consumer $i$ has the following utility for room option $j$ in market $n$ :

$$
u_{i j n}=\mu_{i j n}-\alpha_{i}\left(1+\tau_{j n}\right) p_{j n}+\epsilon_{i j n}
$$

For consumer $i, \mu_{i j n}$ represents a market-specific mean utility for accommodation $j$. The price of an accommodation is denoted $p_{j n}$, while the lodging tax rate is $\tau_{j n}$. Finally, $\epsilon_{i j n}$ is an idiosyncratic component with a type I extreme value distribution. We normalize the value of the outside option to 0 for all markets. This demand specification yields the following quantities for each accommodation type:

$$
Q_{j n}\left(p_{j n}, p_{-j n}\right)=D_{n} \int \frac{e^{\mu_{i j n}-\alpha_{i}\left(1+\tau_{j n}\right) p_{j n}}}{1+\sum_{j^{\prime}} e^{\mu_{i j^{\prime} n}-\alpha_{i}\left(1+\tau_{j n}\right) p_{j^{\prime} n}}} d H\left(\mu_{i j n}, \alpha_{i}\right)
$$

where $D_{n}$ is the market size, and $H$ is the joint distribution of consumer heterogeneity in $\mu_{i j n}$ and $\alpha_{i}$. We allow for consumer heterogeneity in how travelers value the inside options (hotels and Airbnb), the high-end hotel scales (luxury and upper upscale), and accommodation prices. We assume that the distribution of consumer heterogeneity is multivariate normal with a mean and variance matrix to be estimated. We do not allow for correlation across distinct components of consumer heterogeneity. 


\section{Hotel Supply}

Each hotel competes with other hotels of the same scale, hotels of different scales, and peer supply. We assume that this competition takes the form of a Cournot equilibrium. Hotels of type $h$, where $h \in\{l$ luxury, upper-upscale, upscale, upper-midscale, midscale, economy $\}$, have aggregate room capacity $K_{h n}$. Since there are multiple hotels within each scale, we need to distinguish between scale-level and hotel-level quantities. We let $Q_{h n}$ denote the scale-level number of rooms sold. We assume no differentiation in room quality within scale, so the number of rooms sold by each hotel, denoted $q_{h n}$, is the ratio of aggregate quantity divided by the number of hotels. Analogously, scale-level capacity is denoted $K_{h n}$, while hotel-level capacity is $k_{h n}$.

We must also match the fact that prices increase sharply as the number of rooms sold approaches the number of available rooms. In practice, occupancy rates never reach $100 \%$ at the scale level, but prices start increasing before then (Figure 7). This is because, although we model hotels as homogeneous within each scale, some individual hotels may sell out before others and this may result in sharply increasing scale-level prices. In addition, if hotels face uncertainty about the actual level of demand when setting prices, increases in expected demand will increase the probability of hitting capacity constraints, thus increasing prices before realized demand reaches $100 \%$. We allow our model to fit this increasing price profile by estimating an increasing cost function for hotels that kicks in as soon as hotel occupancy is at least $85 \%$ within a scale. The estimation of increasing marginal costs as production approaches capacity constraints was previously used by Ryan (2012) to estimate the cost structure of the cement industry.

We assume that hotels' variable costs are made of two parts: a constant marginal cost $c_{h n}$, and an increasing marginal cost $\gamma_{h n}\left(q_{h n}-\nu k_{h n}\right)$, which starts binding as quantity approaches the capacity constraint. Given the above discussion, we set $\nu=0.85$. So, instead of solving a maximization problem subject to a capacity constraint as in Equation 1, each hotel selects its quantity to maximize the following profit function:

$$
\underset{q_{h n}}{\operatorname{Max}} q_{h n} p_{h n}\left(Q_{h n}, Q_{-h n}, Q_{a n}\right)-q_{h n} c_{h n}-\frac{\gamma_{h n}}{2} \mathbb{1}\left(q_{h n}>\nu k_{h n}\right)\left(q_{h n}-\nu k_{h n}\right)^{2} .
$$

We assume that hotels observe all components of demand and competitors' costs, so that there is no uncertainty about whether $q_{h n}>\nu k_{h n}$ or not. Letting $N_{h n}$ denote the number

of hotels within scale $h$, we have that $q_{h n}=\frac{Q_{h n}}{N_{h n}}$. Taking advantage of the implicit function 
theorem, the optimization problem gives rise to the following first order condition: ${ }^{13}$

$$
p_{h n}=-\frac{1}{N_{h n}} \frac{Q_{h n}}{Q_{h n}^{\prime}}+c_{h n}+\gamma_{h n} \mathbb{1}\left(q_{h n}>\nu k_{h n}\right)\left(q_{h n}-\nu k_{h n}\right)
$$

where $Q_{h n}$ is scale-level room demand from Equation 6, and $Q_{h n}^{\prime}$ is the derivative with respect to its own price.

\section{Peer Supply}

Peers of each quality type $a$, where $a \in\{$ Airbnb luxury, Airbnb upscale, Airbnb midscale, Airbnb economy $\}$, with total available listings $K_{a n}$, take prices as given. Hosts draw marginal costs from a normal distribution with parameters $\omega_{a n}$ and $\sigma_{a n}$. Each draw is iid across hosts and time. Hosts of type $a$ choose to host only if the price $p_{a n}$ is greater than their cost. Therefore, the quantity supplied will be determined by the following equation:

$$
Q_{a n}\left(p_{a n}, p_{-a n}, p_{h n}\right)=K_{a n} \operatorname{Pr}\left(c \leq p_{a n}\right)=K_{a n} \Phi\left(\frac{p_{a n}-\omega_{a n}}{\sigma_{a n}}\right)
$$

\section{Equilibrium}

The market equilibrium consists of prices and quantities for hotels and peer hosts $\left(p_{h n}, p_{a n}\right.$, $\left.Q_{h n}, Q_{a n}\right)$ such that consumers, hotels, and peer hosts make decisions to maximize their surplus, and their optimal choices are consistent with one another.

\subsection{Estimation Strategy}

We estimate the demand, hotel supply, and peer supply separately. For demand, the highlevel choices are the market size, the moments to match, and the instruments used.

Starting first with demand, we need to make a normalization. Since Airbnb listings are on average bigger than hotel rooms and can host more guests, we adjust quantities so that room capacity is comparable across Airbnb listings and hotel rooms. To do this, we take advantage of the fact that we have information on the average number of guests for Airbnb transactions. In addition, lower quality Airbnb listings are typically private rooms with similar capacity as standard hotel rooms. For this reason, we assume that each hotel room is occupied by as many people as the average number of occupants of Airbnb listings in the midscale quality category in the same city. Given this adjustment, our quantities, prices, and estimates should be interpreted as referring to room-nights with standard hotel occupancy.

\footnotetext{
${ }^{13}$ The objective function is not differentiable at $q_{h n}=\nu k_{h n}$, but otherwise the first order condition holds everywhere else.
} 
We use data on the 10 largest cities in terms of the share of Airbnb bookings in our sample. Our initial estimation sample includes all days in 2013 and 2014. We restrict the sample to 10 cities and 2 years of data for two practical reasons. First, in other cities and time periods market shares of Airbnb are often close to zero, which complicates our estimation. Second, there will not be much of an effect of Airbnb when market shares are close to 0. For the same reason, we also drop Airbnb options if their share of available rooms is less than $0.5 \%$ on a given day and city.

One key choice we must make in the estimation is $D_{n}$, the total number of consumers considering to book accommodations. The choice of $D_{n}$ will affect market shares for hotels and Airbnb, as well as the share of potential travelers choosing to stay home, to travel to other locations, or to stay in alternative accommodations, e.g. friends and family. We set $D_{n}$ equal to three times the average number of rooms booked in the corresponding month in each city in 2012. This assumption allows the potential number of travelers to vary seasonally across cities, and it allows for both substitution from hotels - hotel travelers switching to Airbnb -, and market expansion - travelers switching from the outside option to Airbnb. We rationalize any remaining variation over time in the total number of travelers booking accommodations with mean utilities for inside options that vary as a function of observable characteristics such as Google search trends, and unobservables.

The second key choice is the set of moments that we match to the data. We construct two types of moments for the demand estimation: moments to match predicted and realized market shares (market share moments) and one moment to match predicted hotel-Airbnb substitution with substitution obtained from survey responses that Airbnb conducted (substitution moment).

Our market share moments are

$$
m_{1 j n}=\left[\delta_{j n}-\hat{\delta}_{j n}\right] Z_{j n}
$$

where $\delta_{j n}$ is the realized mean utility from accommodation $j$ in market $n$ that rationalizes the observed market shares, and $\hat{\delta}_{j n}$ is the mean utility predicted from the vector of parameters to be estimated. $\hat{\delta}_{j n}$ is the component of utility from Equation 5 that does not differ across individual travelers, and is a function of observable and unobservable shifters of demand for different types of accommodations. The observable shifters include city-scale fixed effects, city-month fixed effects (to account for market specific seasonality), city-specific and Airbnbcity-specific time trends, the log of Google searches and its square, and the log of Airline passengers and its square.

The substitution moment comes from survey data on alternative accommodation choices 
of travelers booking on Airbnb. Airbnb has conducted surveys of guests in four of the sampled cities during 2013 and 2014. The surveys asked the question: "If Airbnb had not been available, what would you have done?". Between $58 \%$ and $81 \%$ of guests across cities said that they would have stayed in a hotel. A simple average across cities yields a substitution share of $68 \%$ towards hotels. ${ }^{14}$

We match the survey moment in our model by computing the share of Airbnb travelers who would have wanted to book a hotel at the observed prices had Airbnb not been available. To predict the share of Airbnb travelers choosing hotels in the absence of Airbnb, we first note that aggregate hotels' market share in market $n$ is $s_{\text {hotels }, n}=\sum_{j \in \text { hotel }} \int \frac{e^{\mu_{i j n}-\alpha_{i}\left(1+\tau_{j n}\right) p_{j n}}}{1+\sum_{j^{\prime}} e^{\mu_{i j^{\prime} n}-\alpha_{i}\left(1+\tau_{j n}\right) p_{j^{\prime} n}}}$ $d H\left(\mu_{i j t}, \alpha_{i}\right)$. Airbnb market share, denoted $s_{a i r b n b, n}$, is similarly computed. If Airbnb listings were not available, hotels' market share would be $s_{\text {hotels, } n^{*}}=\sum_{j \in \text { hotel }} \int \frac{e^{\mu_{i j n}-\alpha_{i}\left(1+\tau_{j n}\right) p_{j n}}}{1+\sum_{j^{\prime} \in \text { hotel }} e^{\mu_{i j^{\prime} n}-\alpha_{i}\left(1+\tau_{j n}\right) p_{j^{\prime} n}}}$ $d H\left(\mu_{i j t}, \alpha_{i}\right)$. Aggregating over all markets gives us the following moment:

$$
m_{2 n}=\sum_{n}\left[D_{n}\left(\frac{s_{h, n^{*}}-s_{h, n}}{s_{a, n}}-s_{\text {survey }}\right)\right]
$$

The final key choice is the set of instruments for the market share moments in Equation 9. We first generate instruments to predict after-tax prices. We use a series of cost-shifters that affect prices and are unlikely to be correlated with demand shocks. These cost-shifters include hotel and Airbnb tax rates, ${ }^{15}$ and specifically for Airbnb, the number of residents traveling out of a city. We also construct instruments using the total number of available rooms. Since for Airbnb room availability responds to demand, the number of available rooms is predicted with city-specific quadratic time trends. We interact the predicted number of available Airbnb rooms with an indicator variable for hotel options, and we do the same for hotel rooms and an indicator variable for Airbnb options. This set of instruments proxy for the level of competition within a market. A hotel scale's own number of available rooms can also be used to construct an instrument because it affects whether hotel capacity constraints are likely to bind. To use it as an instrument, we interact its inverse, and its inverse squared, with the Google search trend, and its square. We use the ratio because capacity constraints affect prices more when demand is higher. Since we have a number of instruments that are

\footnotetext{
${ }^{14}$ In 2015, Morgan Stanley and AlphaWise conducted a representative survey of 4,116 adults in the US, UK, France, and Germany. In the survey, they asked respondents about their travel patterns. $12 \%$ of respondents had used Airbnb within the past year and when asked which travel alternative Airbnb replaced, $42 \%$ of respondents answered a hotel. See Nowak et al. (2015). We think that the major reason for the differences between the Airbnb and Morgan Stanley surveys is that Morgan Stanley sampled guests to all types of destinations including resorts and European cities. There are typically more non-Airbnb and non-hotel options for guests in these locations.

${ }^{15}$ Airbnb started collecting occupancy taxes in Portland, OR on July 1, 2014, and began collecting taxes in San Francisco on October 1, 2014.
} 
potentially weak and correlated with each other, we take the principal components of all the instruments, and keep the components that account for $95 \%$ of the variation (Carrasco $(2012))$.

Once we have predicted prices from the set of instruments presented above, we follow Gandhi and Houde (2016) to construct additional instruments that measure the distance in characteristic space between different accommodation options. The relevant characteristics in our model include the ordering of scales from luxury to economy, and prices. We construct the following instruments: the difference and square of the difference between the predicted price of an option and the predicted price of its closest alternatives - for midscale hotels, the closest alternatives are upper midscale and economy -, the total number of alternatives whose predicted price is within a standard deviation of an option predicted price, and the sum and sum of squares of the difference between the predicted price of a hotel option and the predicted prices of all other hotel options. Since these instruments are highly correlated, we keep the principal components accounting for $75 \%$ of the variation for the estimation. Appendix $\mathrm{C}$ describes these instruments in greater detail. With this list of instruments, we use the moments in equations 9 and 10 to estimate the set of demand parameters by generalized method of moments.

It is useful to give an intuition for how the variation in the data allows us to estimate our demand parameters. Our descriptive statistics show that the prices of hotels and Airbnb options, unadjusted for different number of occupants, are similar. This fact, together with the relatively high substitution rate between hotels and Airbnb rooms derived from survey responses, suggests that the mean utilities of hotels and Airbnb options should be fairly similar. However, in practice we also observe very different market shares, much higher for hotels than for Airbnb options. The market share and substitution moments helps us rationalize these two patterns in the data. On one hand, the substitution moment helps us identify the random coefficient on the inside option, which is common across hotels and Airbnb listings. On the other, differences in market shares rationalize mean utilities that will be higher for hotels than for Airbnb options. Finally, differences in market shares when the price of competitors change help us identify consumer preference heterogeneity across options and prices.

Once we obtain demand estimates that let us compute $Q_{h n}$ and its derivative, we estimate the supply function from equation 7 using a linear IV approach:

$$
p_{h n}+\frac{1}{N_{h n}} \frac{Q_{h n}}{Q_{h n}^{\prime}}=\theta X_{h n}+\gamma_{h n} \mathbb{1}\left(q_{h n}>\nu k_{h n}\right)\left(q_{h n}-\nu k_{h n}\right)+\epsilon_{h n} .
$$

$X_{h n}$ includes city-scale fixed effects and city-specific linear time trends. We allow $\gamma_{h n}$ to vary 
by city and scale.

We instrument for the increasing cost component using interactions of the Google search trend with city and hotel fixed effects. We use these instruments because they affect hotel prices only by increasing the likelihood that capacity constraints bind. We estimate the supply equation separately for each day of the week to allow for the possibility that staffing requirements and hotels' response to capacity constraints vary across days of the week.

Finally, the supply of Airbnb can be estimated separately using another set of linear IV regressions for the same sample period. Equation 8 implies that $\Phi^{-1}\left(\frac{Q_{a n}}{K_{a n}}\right)=\frac{\omega_{a n}}{\sigma_{a n}}+\frac{1}{\sigma_{a n}} p_{a n}$, where the left-hand side is the inverse of a standard normal cumulative distribution function calculated at a value equal to the share of booked rooms out of all Airbnb listings. We estimate this equation separately for each listing type using the specification

$$
\Phi^{-1}\left(\frac{Q_{a n}}{K_{a n}}\right)=\beta_{a} p_{a n}+\gamma_{a} X_{a n}+\epsilon_{a n}
$$

where $K_{a n}$ is the number of active Airbnb listings, $p_{a n}$ is the average transacted price of Airbnb type $a$ in market $n$, and $X_{a n}$ include year-month fixed effects, city fixed effects, and city-specific linear time trends. Here we choose $K_{a n}$ to be the number of active listings because the decision of being available is a choice of the host that depends on his own marginal cost draw. We instrument for the transacted price with log of (de-trended) Google search trends and the log of incoming air passengers.

After estimating the above equation, we can transform the coefficients into the following peer cost parameters:

$$
\sigma_{a n}=\frac{1}{\beta_{a}}, \omega_{a n}=\frac{\gamma_{a} X_{a n}+\epsilon_{a n}}{\beta_{a}} .
$$

\section{Results}

In this section, we discuss the results of our estimation. We first go over our estimated parameters. Then we discuss the effects of Airbnb on consumer surplus. Lastly, we study the effects on hotels' and hosts' bookings, revenues, and surplus. For each of these outcomes, we discuss heterogeneity across cities and time periods.

\subsection{Parameter Estimates}

Table 7 displays the estimates of demand parameters that are common across cities and accommodation options. We first discuss the parameters governing the distribution of price sensitivity across travelers. The mean price coefficient is -.033 and the standard deviation is 
.006. The standard deviation is imprecisely estimated, but our estimates are consistent with existing work on hotel demand (Koulayev (2014)). Google search trends and incoming airline travelers are estimated to have a positive effect on demand for the range of values observed in the data. We also estimate large and statistically significant heterogeneity in preferences for high-end hotel options - luxury and upper upscale - and a more limited but equally significant level of heterogeneity in preferences between traveling or not. This last estimate of the random coefficient on the inside option is especially important because it governs the extent to which Airbnb travelers would substitute towards hotels or the outside option if Airbnb were not available. The model achieves a value for the objective function of 170 with a relatively parsimonious specification. The total number of observations in the data is 65,172 while we estimate 375 linear parameters and 3 non-linear parameters determining the variances of the random coefficients.

Next, we consider the mean utilities across accommodation options. Figure 8 displays the mean willingness to pay per night for each option and city at the end of 2014. The fact that some values are negative reflects our choice of a market size that's three times the average number of booked rooms in a city-month. When looking at the mean utilities in relative terms, our estimates show that willingness to pay tends to be decreasing between upscale and economy hotels and between Airbnb luxury and economy listings. The extremely low mean utilities for luxury and upper upscale hotels are rationalized by the fact that preferences for these options are highly heterogeneous, as highlighted in Table 7.

The value of the top Airbnb option is lower than the value of the lowest hotel option across all cities, with some variation in the relative differences. We cannot distinguish between alternative explanations for this difference, but one likely possibility is that not all travelers actually consider Airbnb as a viable option for their travel plans, yet. Another possibility is that Airbnb listings are typically located farther away from the city tourist and business centers, which might lower travelers' willingness to pay relative to hotels.

Table A5 shows the city-specific elasticities of demand for different accommodations with respect to their own price and Table A6 shows the average cross-price elasticities. We find that demand for accommodations is elastic on average. For example, in New York, the demand elasticities range between -8.54 for luxury hotels and -2.93 for the lowest quality of Airbnb listings. There is also substantial variation across cities in demand elasticities, ranging between -2.65 in Portland and -6.24 in New York for midscale hotels.

Next, we turn to the estimates of hotel cost parameters. Our parameter estimates are precise and the estimation procedure explains most of the variation with an R-squared of 0.83. The interquartile range for the errors is $-\$ 9.9$ to $\$ 12.2 .^{16}$ Figure 9 plots the marginal cost curves for different hotel scales and different cities at the end of 2014. We find that 
the constant components of hotels' marginal costs have the expected relationship with hotel quality. The marginal cost for luxury hotels in New York city are \$324 on average. We want to be careful in not interpreting these costs as actual expenditures per night-booked. Research by Kalnins (2006) suggests that due to reputational concerns, hotels tend to have a price threshold below which they will not go, and this threshold is typically higher than the cost of an additional maid- or clerk-hour. We view our estimates as reflecting this price threshold. The figure also plots the increasing component of hotels' marginal costs. We find that for all but one of the city and hotel combinations, marginal costs increase relatively steeply with quantity when hotel occupancy reaches $85 \%$. This increasing cost reflects the fact that regardless of the level of competition, hotels will increase their prices as they approach full capacity. Tables A7 and A8 report the full set of city-scale cost estimates.

Finally, Figure 10 displays the mean costs over time for listings in New York City. Costs vary over the course of the year, and there is a slightly increasing trend for all room options. In New York but also in other cities, costs increase monotonically in listing quality, and the mean costs exceed the mean transacted prices. These relatively high costs stem from the fact that fewer than $50 \%$ of active listings on Airbnb typically transact (Table 1). With R-squared values ranging from .34 to .46, the variation in our data can explain a little less of Airbnb costs than hotels' costs. However, we estimate economically and statistically significant dispersion in the cost distribution for all listing types, which explains the high supply elasticity of Airbnb accommodations. Interestingly, costs go up during New Year's Eve and other high seasons. This may reflect the fact that travelers during those times are costlier to host, maybe because of their higher likelihood to be disruptive. Alternatively, it may mean that during those periods hosts prefer to stay in their apartments with friends and family rather than strangers. Table A9 displays the full set of estimates of Airbnb costs by listing type and city. The next section uses the estimates presented above to compare realized welfare to a world without Airbnb.

\subsection{Counterfactual Analysis}

We present two counterfactual scenarios without Airbnb, and describe the effect that the absence of Airbnb would have for consumers, hotels, and peer hosts. The first counterfactual scenario ignores hotel capacity constraints and how hotel prices would change if Airbnb were not available. In this scenario, travelers who booked on Airbnb are allowed to book any hotel option at the prevailing prices, regardless of actual room availability. The second counterfactual scenario allows hotels to adjust prices in response to the absence of competing

\footnotetext{
${ }^{16}$ We also conducted a 10 -folds cross-validation and found that the mean absolute error is similar between estimation sample and hold-out sample, suggesting that we're not over-fitting.
} 
accommodations on Airbnb. This counterfactual requires computing new Cournot equilibria for each market with demand and hotel cost parameters taken from our estimates. ${ }^{17} \mathrm{We}$ refer to the first counterfactual as the 'unconstrained' scenario, and to the second as the scenario with 'price adjustment'.

We discuss consumer surplus first. Table 8 presents how consumer surplus would change in 2014 without Airbnb. The table shows that there would be a $\$ 143$ million loss in consumer surplus if we could ignore hotels' capacity constraints and price adjustments. This loss corresponds to $\$ 21$ per room-night, about $15 \%$ of the purchase price. The consumer surplus loss in this scenario only measures one channel through which Airbnb benefits consumers, i.e. product differentiation.

Relative to the 'unconstrained' counterfactual, there are two additional mechanisms through which the 'price adjustment' counterfactual hurts consumers. First, travelers who booked on Airbnb now face higher hotel prices. Second, travelers who previously booked hotel accommodations also face higher prices. The consumer surplus loss in this scenario almost doubles, rising to $\$ 276$ million. This loss corresponds to $\$ 41$ per room-night.

We can also look at how consumer surplus losses vary across cities and time periods. The total surplus from Airbnb is primarily determined by the number of Airbnb bookings in that city. This means that the greatest aggregate losses from the removal of Airbnb are in New York, Los Angeles, and San Francisco. On a per room-night basis, the surplus change is greatest for Seattle and lowest for Miami.

We also split our sample into 'compression nights', defined by the lodging industry to be nights when hotels reach $95 \%$ occupancy, and non-compression nights. The surplus per night booked is bigger on compression nights $(\$ 57)$ than on non-compression nights $(\$ 36)$. This effect is not due to travelers liking Airbnb more on these nights - the surplus per night in the unconstrained counterfactual is nearly identical between these periods. Instead, the effect comes from the supply side. When comparing the surplus per night between the counterfactual with and without price adjustments, there is a $\$ 35$ difference during compression nights versus $\$ 14$ for non-compression nights. This occurs because hotels can charge high prices during compression nights and the elastic host supply keep prices down.

We now turn to the effects of Airbnb on hotels. If hotels did not have capacity constraints, Table 10 shows that hotels would increase the number of sold rooms by $2 \%$. However, when

\footnotetext{
${ }^{17}$ Our estimation procedure doesn't guarantee that, in the absence of Airbnb, the equilibrium quantities remain below hotel capacity. We add an additional, although rarely binding, constraint in the price adjustment equilibrium which ensures that hotel quantities do not exceed an appropriately defined measure of hotel capacity for each hotel type and period. We define the threshold to be the maximum between 95\% occupancy, the 99th percentile if occupancy for the city-scale and the observed occupancy level for a particular hotel scale in a given city-day.
} 
we account for capacity constraints and the increase in hotel prices, sold rooms would only increase by $1.3 \%$, for a revenue increase of $1.5 \%$. This corresponds to a gain of $\$ 412$ million in revenue for hotels.

The effects of Airbnb on hotel revenues are heterogeneous across cities and over time. For example, in New York, bookings would increase by $2 \%$ and revenue would increase by $2.24 \%$ without Airbnb. In contrast, in San Jose, a city where hotels are less likely to hit their capacity constraints, bookings would increase by $.63 \%$ and revenues would increase by $.72 \%$. There is also heterogeneity in effects across high and low demand days. Hotel bookings increase by just .99\% on compression nights but revenues increase by $1.7 \%$. On the rest of the nights, bookings and revenues would both increase by about $1.4 \%$. The difference across nights demonstrates that the effect of Airbnb on hotels is more concentrated on prices than quantities during high-demand days relative to low-demand days. If we take our cost estimates seriously, we can also look at the effect of Airbnb on hotel profits, which we calculate as hotel revenue minus the non-increasing part of the cost function. We find that profits would increase by $3.69 \%$ on average across all of the cities in the sample, with the largest increase happening in New York.

We should note that our estimates give us a lower bound for hotel variable profit loss - or an upper bound on the percent change. This is because the profit change does not directly correspond to hotel surplus for at least three reasons. First, hotels earn additional revenues through complimentary services such as conferences and food sales, but also incur additional costs. Second, there are fixed costs involved in operating a hotel which we do not model in this exercise. If competition from Airbnb is strong enough, then some hotels may close down or new hotels may not be built. Third, our marginal cost estimates correspond in part to reputation costs rather than 'true' marginal costs. These additional costs and revenues do not allow us to state with certainty whether hotel surplus is larger or smaller than our profit estimate. $^{18}$

Before moving to the surplus of peer hosts, we consider the extent to which Airbnb expands the market versus cannibalizes hotel demand. Table 11 displays results on the share of Airbnb travelers who would have booked a hotel room in the absence of Airbnb. In the 'unconstrained' scenario, between $27 \%$ and $34 \%$ of Airbnb bookings would not have resulted in a hotel booking, which is broadly consistent with the survey moment used to estimate demand. The market expansion effect becomes much bigger when we account for capacity constraints and hotels' price responses. The share of Airbnb travelers who would have not

\footnotetext{
${ }^{18}$ In Appendix Table A10 we display the results assuming an alternative measure of costs for hotels imputed from the wage bill of hotels in the STR data and trends in the wages of maids across cities and over time. This is likely a lower bound on the true marginal cost of hotels.
} 
in fact booked a hotel room ranges between $42 \%$ in Portland to $63 \%$ in New York.

Not surprisingly, peer hosts would lose without Airbnb. We use the estimated cost distributions of hosts to back out the surplus that they receive from hosting on Airbnb. The surplus for each day can be calculated using the following expression $P S_{a n}=\int_{-I n f}^{p_{a n}}\left(p_{a n}-\right.$ $\max (c, 0)) d F_{a n}(c)$, where we censor the cost distribution at 0 . Note that this expression ignores the variable costs of being listed for a given day, which are likely to be negligible, and the fixed costs of entry into the platform.

Table 12 displays average surplus per room-night and total surplus in 2014. The typical surplus per night ranges between $\$ 23$ in Miami and $\$ 30$ in Austin. Across all bookings in these cities, the average surplus is around $\$ 26$ and does not vary much across high and low demand days. In the aggregate, peer hosts enjoy $\$ 19$ million in producer surplus, with hosts in New York City, Los Angeles, and San Francisco getting the majority of it. Almost half of this surplus is concentrated on compression nights, which comprise only $20 \%$ of all nights.

\section{Conclusion}

We have studied the economics of peer production in the lodging industry. We first documented the determinants of peer supply and showed how market-specific factors such as supply constraints and the costs of hosting affect whether peer production is viable in a given city. We then documented that peer supply is twice as elastic as hotel supply in the short-run.

The highly elastic host supply implies that the largest effects of Airbnb occur in markets where hotels are often near full capacity. We presented a simple model of competition between peer supply and hotels, and tested its implications using data from 50 major US cities. We confirm that the entry of Airbnb negatively affects hotel revenues in cities where hotels are more likely to be capacity-constrained, and that the effect is more concentrated on price than on quantity, at least compared to non-capacity-constrained cities.

Next, we estimated our short-run equilibrium model to study the surplus and market expansion effects of Airbnb. The availability of peer hosts generates $\$ 41$ of surplus per room-night in 2014. This surplus comes both from new bookings generated on Airbnb and from lower prices paid by hotel travelers. In total, Airbnb generates $\$ 276$ million in consumer surplus in 2014 for the 10 largest US cities.

We showed that Airbnb has also affected producers. Without Airbnb, hotel revenues would be $1.5 \%$ higher. Nonetheless, between $42 \%$ and $63 \%$ of nights booked on Airbnb would not have resulted in a hotel booking in the absence of Airbnb. These travelers would have instead chosen the outside option, which could represent staying with friends or family, 
staying at a non-hotel accommodation, booking fewer nights, or not traveling to the city at all. Lastly, peer hosts also benefit from the introduction of Airbnb. Their average surplus per night from hosting is $\$ 26$, which totals $\$ 19$ million in the estimation sample.

Our data only extend through the end of 2014. Since then, Airbnb has continued its rapid growth in both active listings and global awareness. While we cannot say how large its effects have been since then, our paper documents two fundamental reasons why peer production is valuable in the accommodation industry. First, peers offer a differentiated product that is not a perfect substitute to hotel rooms and is valued by consumers. Second, the hotel sector in many cities is frequently constrained by a limited number of available rooms, which lead to high prices during demand peaks because hotels cannot accommodate all potential travelers. Peer production expands available supply at exactly these times of peak demand, thus reducing hotel pricing power and increasing consumer surplus.

Our paper also informs the active policy debate regarding whether and how to regulate peer-to-peer accommodations. Proposed policies include fees and taxes, mandated registrations, quotas, caps on the number of nights per hosts, and bans. ${ }^{19}$ While we cannot conduct a full welfare analysis of these policies due to the other markets affected, our analysis suggests that Airbnb is especially beneficial to consumer and host welfare during peak demand periods in hotel constrained cities.

We have focused on the short-run effects of a peer-to-peer platform on the agents directly involved - hotels, peer hosts, and travelers - without highlighting the platform's own costs and revenues. In the longer run, the number of hotel rooms may also adjust to peer entry. Peer production can have externalities and spillovers into other markets, including the labor and housing markets (Filippas and Horton (2017), Barron et al. (2017)). We leave the study of these effects for future work.

\section{References}

Aguiar, Luis, and Joel Waldfogel. 2015. "Streaming Reaches Flood Stage: Does Spotify Stimulate or Depress Music Sales?" National Bureau of Economic Research Working Paper 21653.

Barron, Kyle, Edward Kung, and Davide Proserpio. 2017. "The Sharing Economy and Housing Affordability: Evidence from Airbnb."

Bass, Frank. 1969. "A New Product Growth for Model Consumer Durables." Management Science, 15(5): 215-227.

\footnotetext{
${ }^{19}$ See https://www . airbnb.com/help/article/1376/responsible-hosting-in-the-united-states.
} 
Berry, Steven, James Levinsohn, and Ariel Pakes. 1995. "Automobile Prices in Market Equilibrium." Econometrica, 63(4): 841-890.

Bolton, Gary, Ben Greiner, and Axel Ockenfels. 2012. "Engineering Trust: Reciprocity in the Production of Reputation Information." Management Science, 59(2): 265285.

Bulow, Jeremy I., John D. Geanakoplos, and Paul D. Klemperer. 1985. "Multimarket Oligopoly: Strategic Substitutes and Complements." Journal of Political Economy, 93(3): 488-511.

Carrasco, Marine. 2012. "A Regularization Approach to the Many Instruments Problem." Journal of Econometrics, 170(2): 383-398.

Chen, K. M., and Michael Sheldon. 2015. "Dynamic Pricing in a Labor Market: Surge Pricing and Flexible Work on the Uber Platform." Mimeo, UCLA.

Cohen, Peter, Robert Hahn, Jonathan Hall, Steven Levitt, and Robert Metcalfe. 2016. "Using Big Data to Estimate Consumer Surplus: The Case of Uber." National Bureau of Economic Research Working Paper 22627.

Cullen, Zoë, and Chiara Farronato. 2017. "Outsourcing Tasks Online: Matching Supply and Demand on Peer-to-Peer Internet Platforms."

Einav, Liran, Chiara Farronato, Jonathan Levin, and Neel Sundaresan. Forthcoming. "Auctions versus Posted Prices in Online Markets." Journal of Political Economy.

Filippas, Apostolos, and John J. Horton. 2017. "The Tragedy of Your Upstairs Neighbors: Is the Airbnb Negative Externality Internalized?" ArXiv e-prints, arXiv:1611.05688.

Fradkin, Andrey. 2017. "Search, Matching, and the Role of Digital Marketplace Design in Enabling Trade: Evidence from Airbnb."

Fradkin, Andrey, Elena Grewal, David Holtz, and Matthew Pearson. 2017. "The Determinants of Online Review Informativeness: Evidence from Field Experiments on Airbnb."

Fraiberger, Samuel P., and Arun Sundararajan. 2015. "Peer-to-Peer Rental Markets in the Sharing Economy." Social Science Research Network SSRN Scholarly Paper ID 2574337, Rochester, NY. 
Gandhi, Amit, and Jean-François Houde. 2016. "Measuring Substitution Patterns in Differentiated Products Industries." University of Wisconsin-Madison and Wharton School.

Griliches, Zvi. 1957. "Hybrid Corn: An Exploration in the Economics of Technological Change." Econometrica, 25(4): 501-522.

Gyourko, J., A. Saiz, and A. Summers. 2008. "A New Measure of the Local Regulatory Environment for Housing Markets: The Wharton Residential Land Use Regulatory Index." Urban Studies, 45(3): 693-729.

Hall, Jonathan, Cory Kendrick, and Chris Nosko. 2016. "The Effects of Uber's Surge Pricing: A Case Study."

Horton, John J. 2016. "Misdirected Search Effort in a Matching Market: Causes, Consequences and a Partial Solution." Working Paper.

Horton, John J., and Richard J. Zeckhauser. 2016. "Owning, Using and Renting: Some Simple Economics of the" Sharing Economy"." National Bureau of Economic Research.

Kalnins, Arturs. 2006. "Markets: The U.S. Lodging Industry." The Journal of Economic Perspectives, 20(4).

Koulayev, Sergei. 2014. "Search for Differentiated Products: Identification and Estimation." The RAND Journal of Economics, 45(3): 553-575.

Kroft, Kory, and Devin G. Pope. 2014. "Does Online Search Crowd Out Traditional Search and Improve Matching Efficiency? Evidence from Craigslist." Journal of Labor Economics, 32(2): 259-303.

Lam, Tom, and Meng Liu. 2017. "Demand and Consumer Surplus in the On-Demand Economy: The Case of Ride Sharing."

Lewis, Gregory, and Georgios Zervas. 2016. "The Welfare Impact of Consumer Reviews: A Case Study of the Hotel Industry."

Nosko, Chris, and Steven Tadelis. 2015. "The Limits of Reputation in Platform Markets: An Empirical Analysis and Field Experiment."

Nowak, Brian, Thomas Allen, Jamie Rollo, Vaughan Lewis, Lin He, Ananda Chen, Wilson W. Ng, Michael Costantini, Owen Hyde, Kevin Liu, Mark 
Savino, Baset A. Chadhry, Anne M. Grube, and Ed Young. 2015. "Global Insight: Who Will Airbnb Hurt More - Hotels or OTAs?" Morgan Stanley.

Petrin, Amil. 2002. "Quantifying the benefits of new products: The case of the minivan." Journal of political Economy, 110(4): 705-729.

Ryan, Stephen P. 2012. "The Costs of Environmental Regulation in a Concentrated Industry." Econometrica, 80(3): 1019-1061.

Saiz, Albert. 2010. "The Geographic Determinants of Housing Supply." The Quarterly Journal of Economics, 125(3): 1253-1296.

Seamans, Robert, and Feng Zhu. 2014. "Responses to Entry in Multi-Sided Markets: The Impact of Craigslist on Local Newspapers." Management Science, 60(2): 476-493.

Zervas, Georgios, Davide Proserpio, and John Byers. 2015. "The Rise of the Sharing Economy: Estimating the Impact of Airbnb on the Hotel Industry." Social Science Research Network SSRN Scholarly Paper ID 2366898, Rochester, NY. 


\section{Figures}

Figure 1: Growth of Airbnb

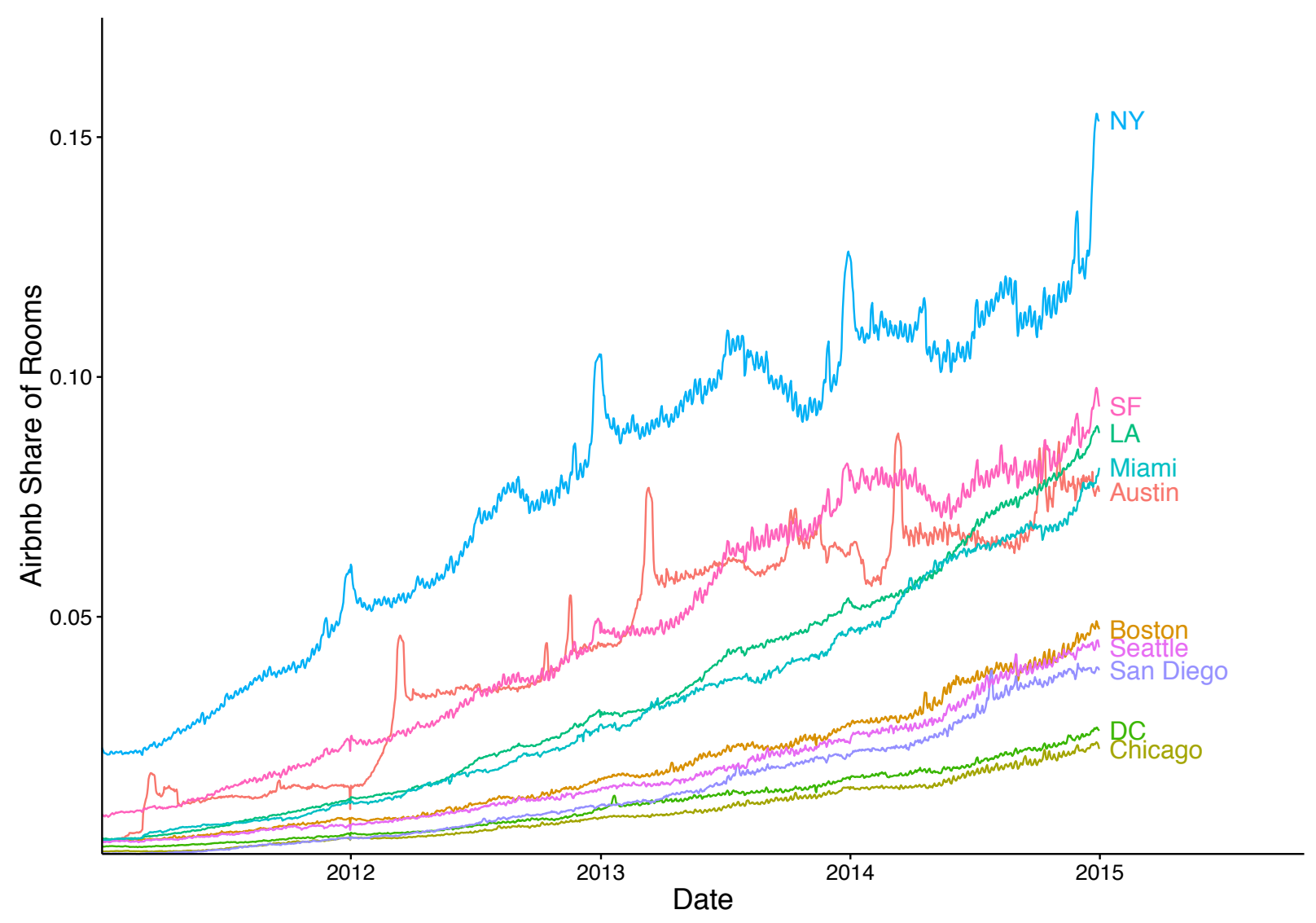

The figure plots the size of Airbnb over time in 10 selected cities. The y-axis is the monthly average of the daily share of Airbnb listings out of all (hotel and Airbnb) rooms available for short-term accommodation. The 10 selected cities are those with the largest number of listings on Airbnb as of December 2014 among the 50 US major cities. 
Figure 2: Predictions on the Effect of Peer Supply on Hotels

(a) Unconstrained Equilibrium

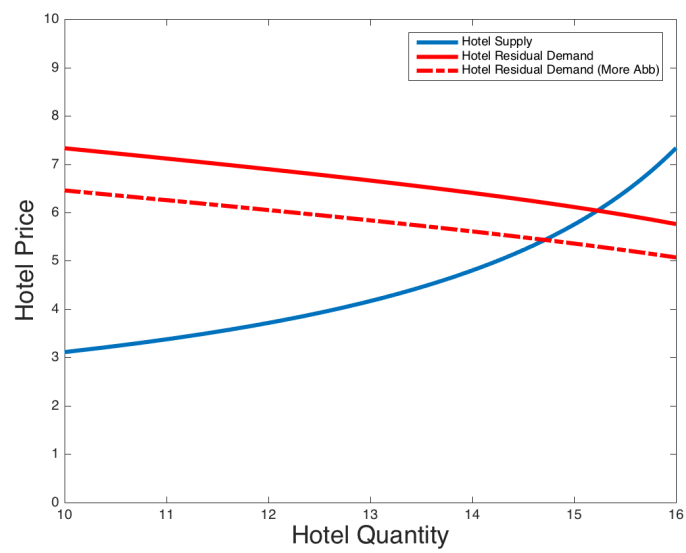

(b) Constrained Equilibrium

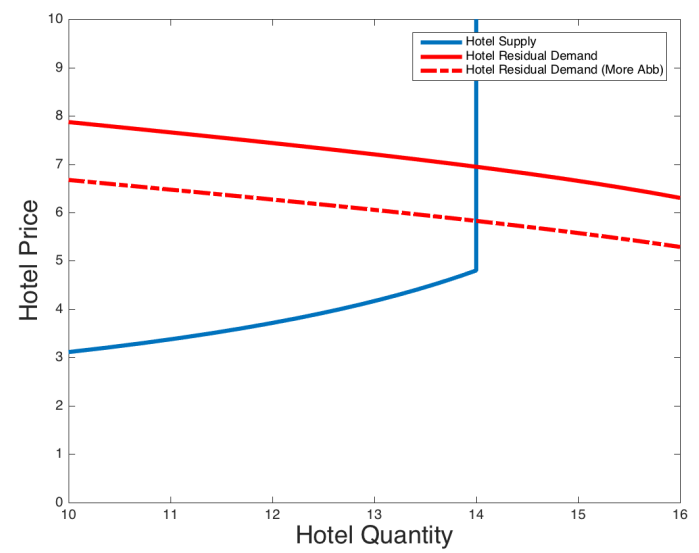

The figures plot the supply and demand curve for hotel rooms in two scenarios. The hotel supply curve is drawn holding constant the price of peer rooms $p_{a}$, varying the demand state $d$, and letting the hotel set the price to maximize its profits as in equation 1. The left panel displays an unconstrained equilibrium, while the right panel displays an equilibrium where the hotel capacity constraint is binding. Peer entry represents a downward shift in demand for hotel rooms. This downward shift will affect hotel quantity relatively more when the hotel supply curve is more elastic. The opposite is true for the effect on hotel prices, which is higher in the capacity-constrained equilibrium. 
Figure 3: Peer Production and Hotel Revenues

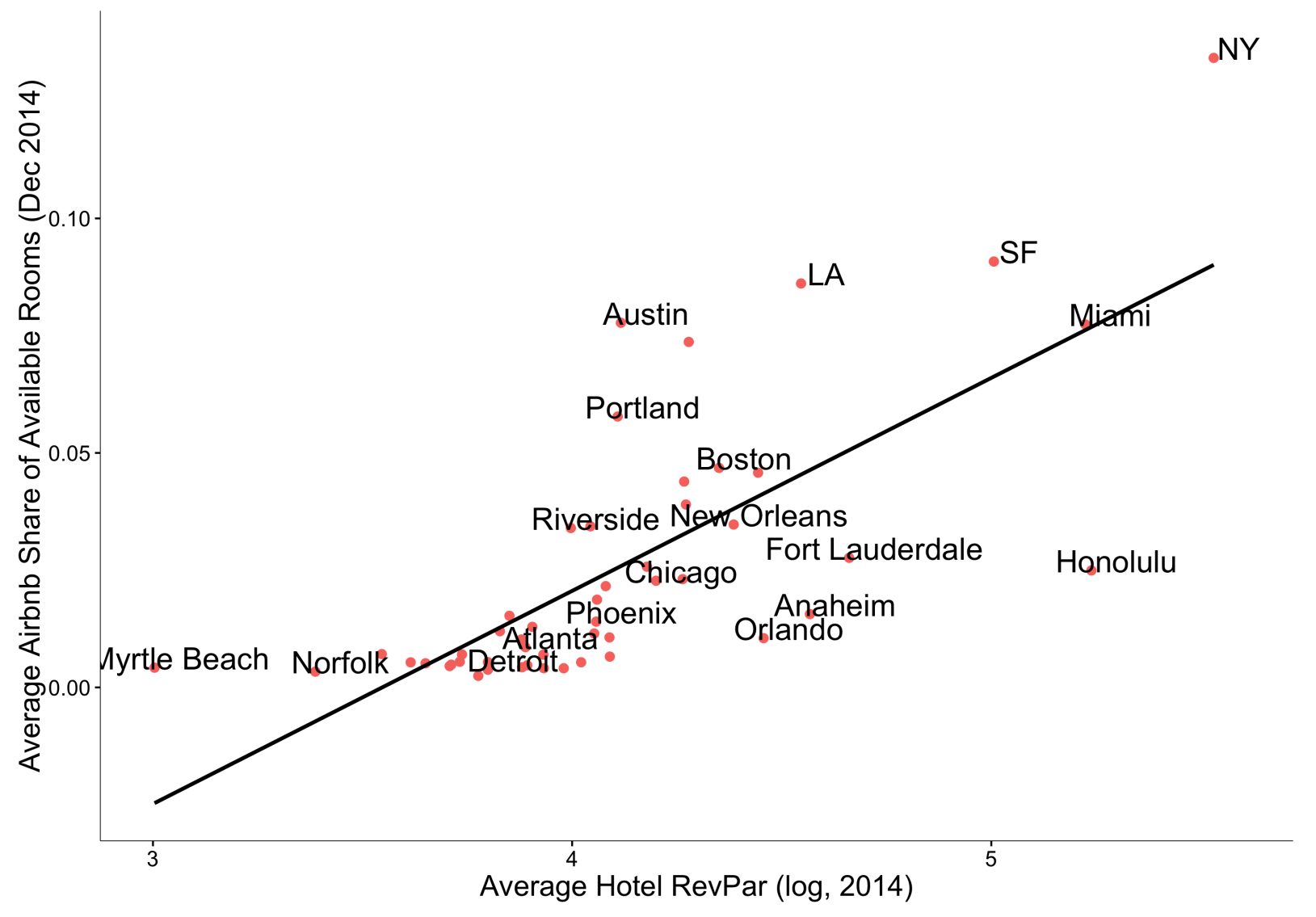

This figure plots the supply share of Airbnb against the average revenue per available room in each respective city. 
Figure 4: Peer Production and Fixed or Marginal Costs

(a) Hotel Supply Constraints

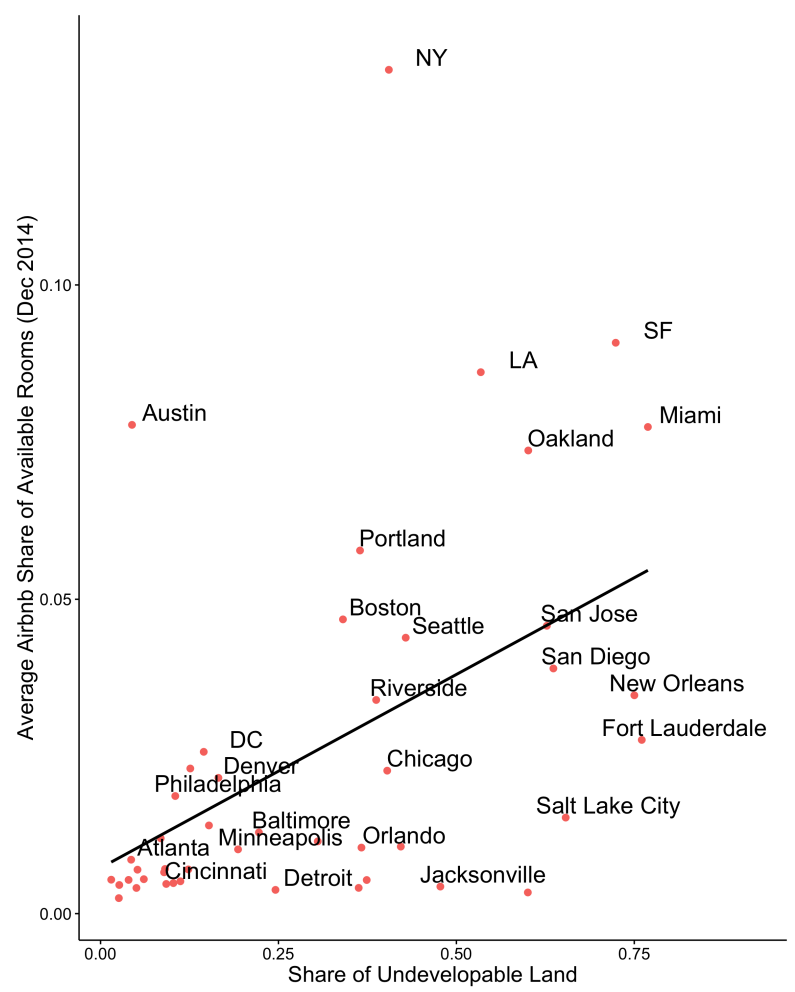

(b) Peers' Marginal Costs

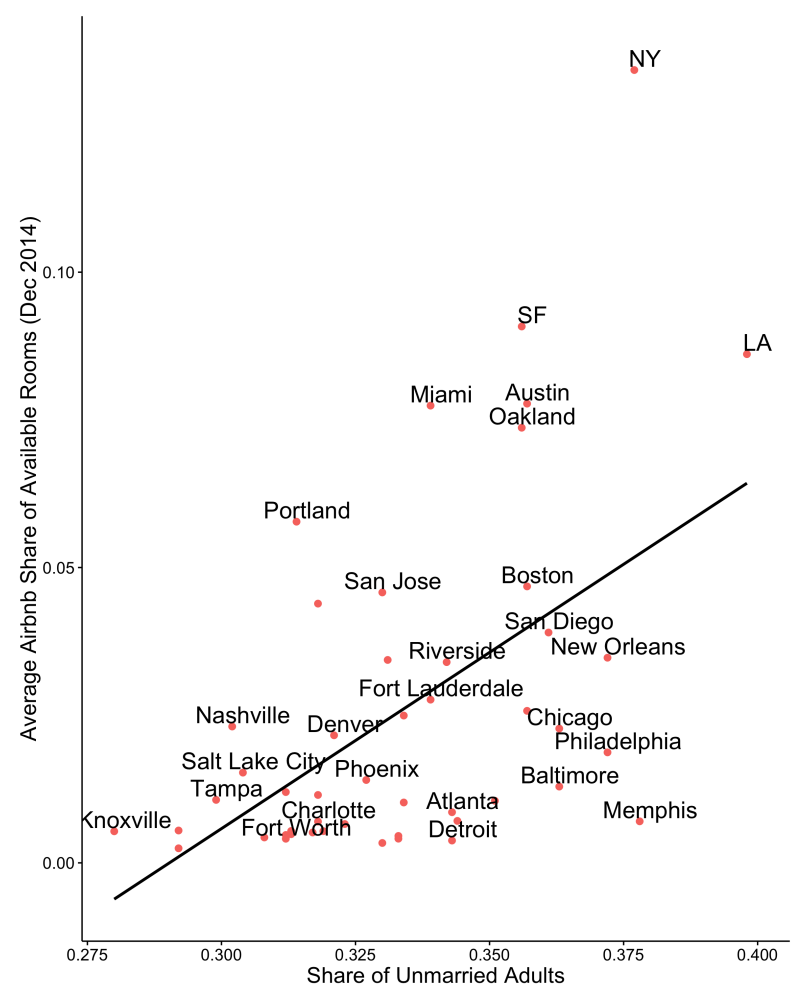

The figures plot the size of Airbnb against a proxy for hotel investment costs (left panel) and a proxy for peers' marginal costs (right panel). The proxy for the constraints to the construction of new hotels is the share of undevelopable area developed by Saiz (2010). This index measures the share of a city that is undevelopable due to geographic constraints, like steep mountains or the ocean. The proxy for peers' marginal costs is the share of unmarried adults in the MSA. The size of Airbnb is measured as the average share of available listings in the last quarter of 2014. Figure A2 in the Appendix confirms that other proxies such as regulatory constraints, the share of children, and the rent to income ratio are also good predictors of peer entry. 
Figure 5: Peer Production and Demand Characteristics

(a) Demand Growth

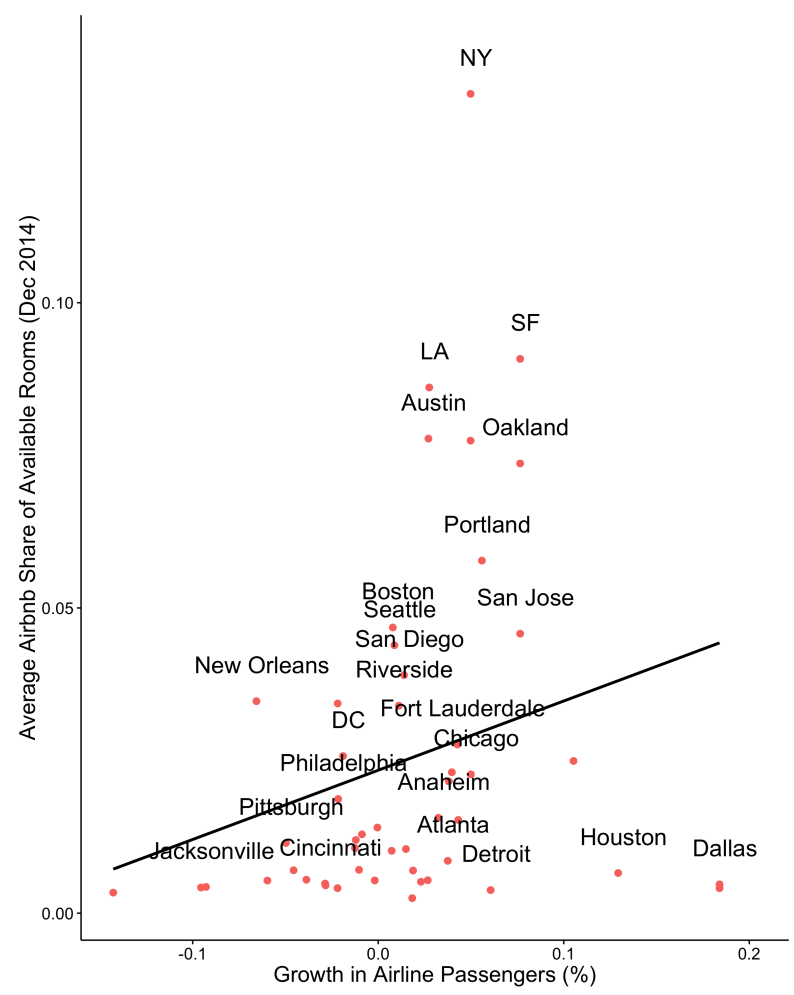

(b) Demand Variability

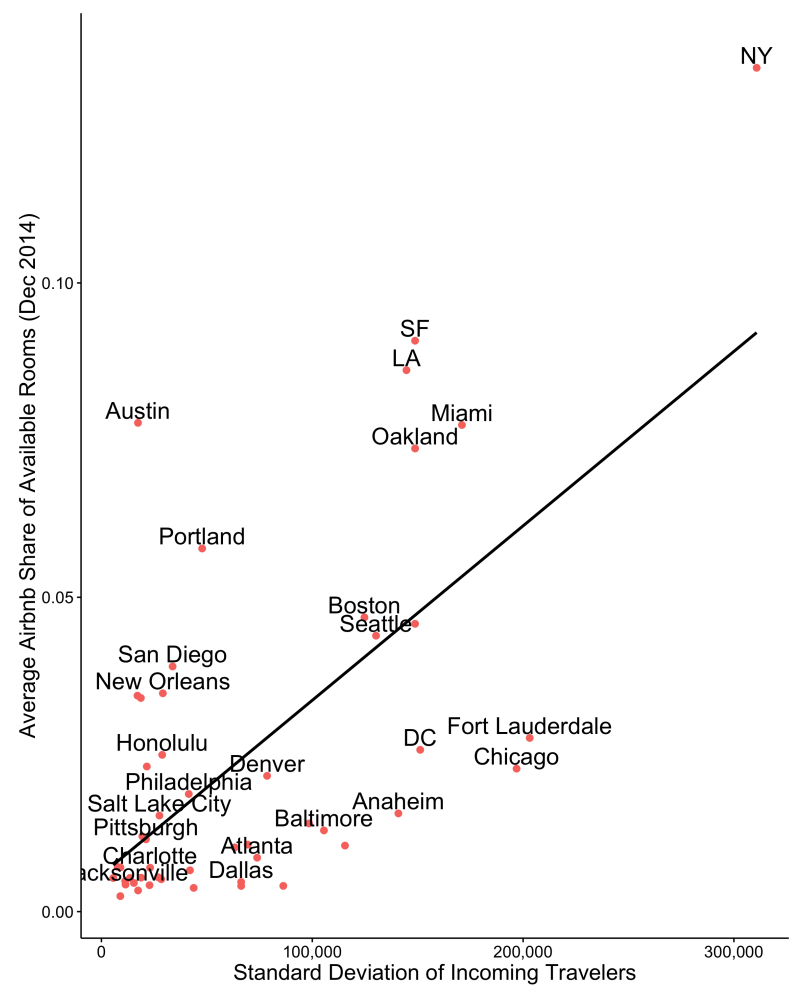

The figures plot the size of Airbnb against the growth rate in incoming air passengers to an MSA between June 2011 and June 2012 (left) and against the standard deviation of incoming air passengers (right). The standard deviation of air travelers is measured using 2011 monthly data on arriving (not returning) passengers at major US airports. We focus on data from 2011-2012, when Airbnb was very small relative to the accommodation market, to limit the possibility that the availability of Airbnb hosts could generate such growth or variability in demand. The size of Airbnb is measured as the average share of available listings in the last quarter of 2014. 
Figure 6: Measures of Airbnb Supply: Demand-induced Calendar Updates

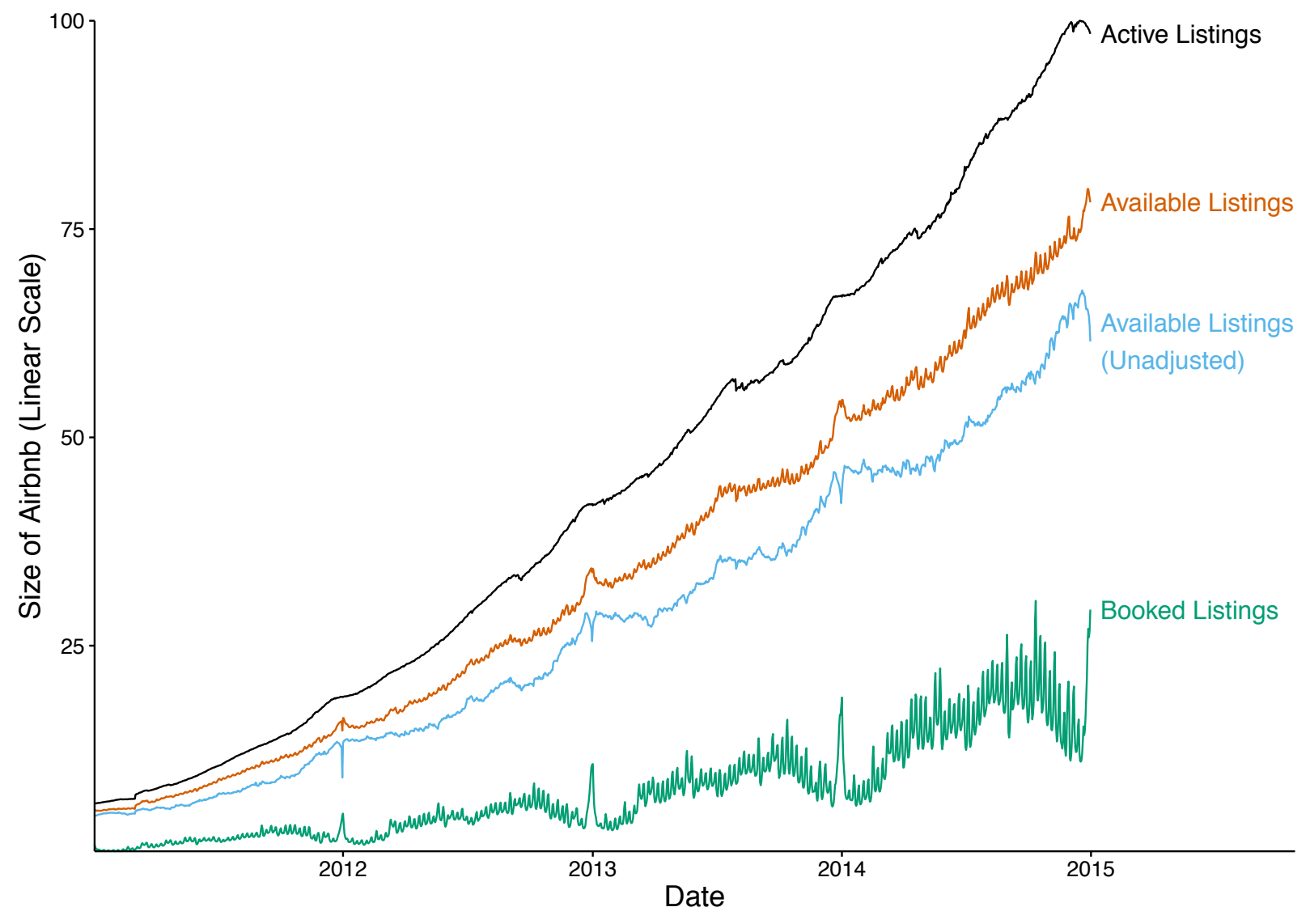

This figure plots four measures of the size of Airbnb. An active listing is defined as a listing available to be booked or booked for any future date. An (unadjusted) available listing is one that is either booked or has an open calendar slot on the date of stay. Available listings augment the unadjusted measure with listings that were contacted for a particular date of stay and were later updated to be unavailable for that date. A booked listing is one that has been booked for that date. 
Figure 7: Prices and Occupancy Rates

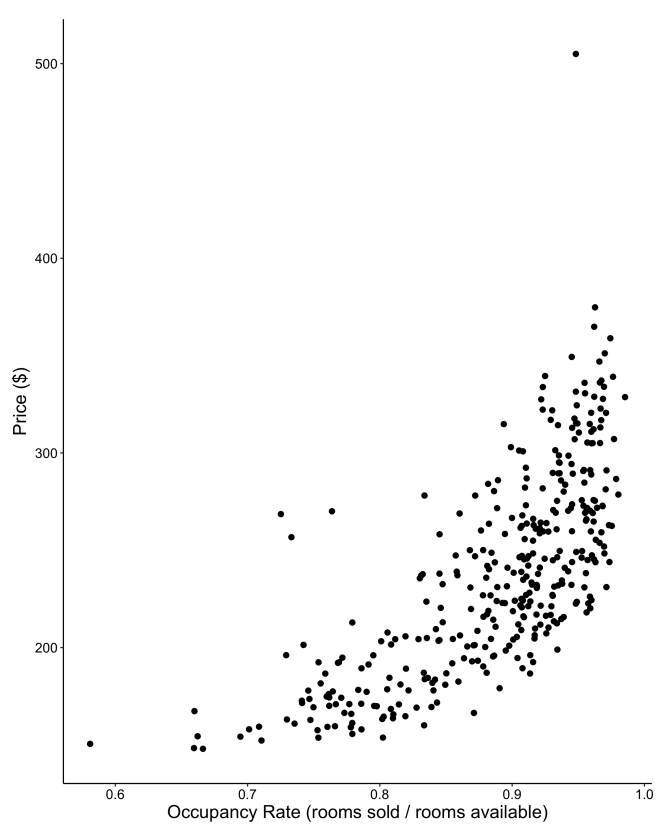

This figure plots prices and occupancy rates of upscale hotels in New York in 2014.

Figure 8: Estimated Utilities for Accommodation Options Across Cities

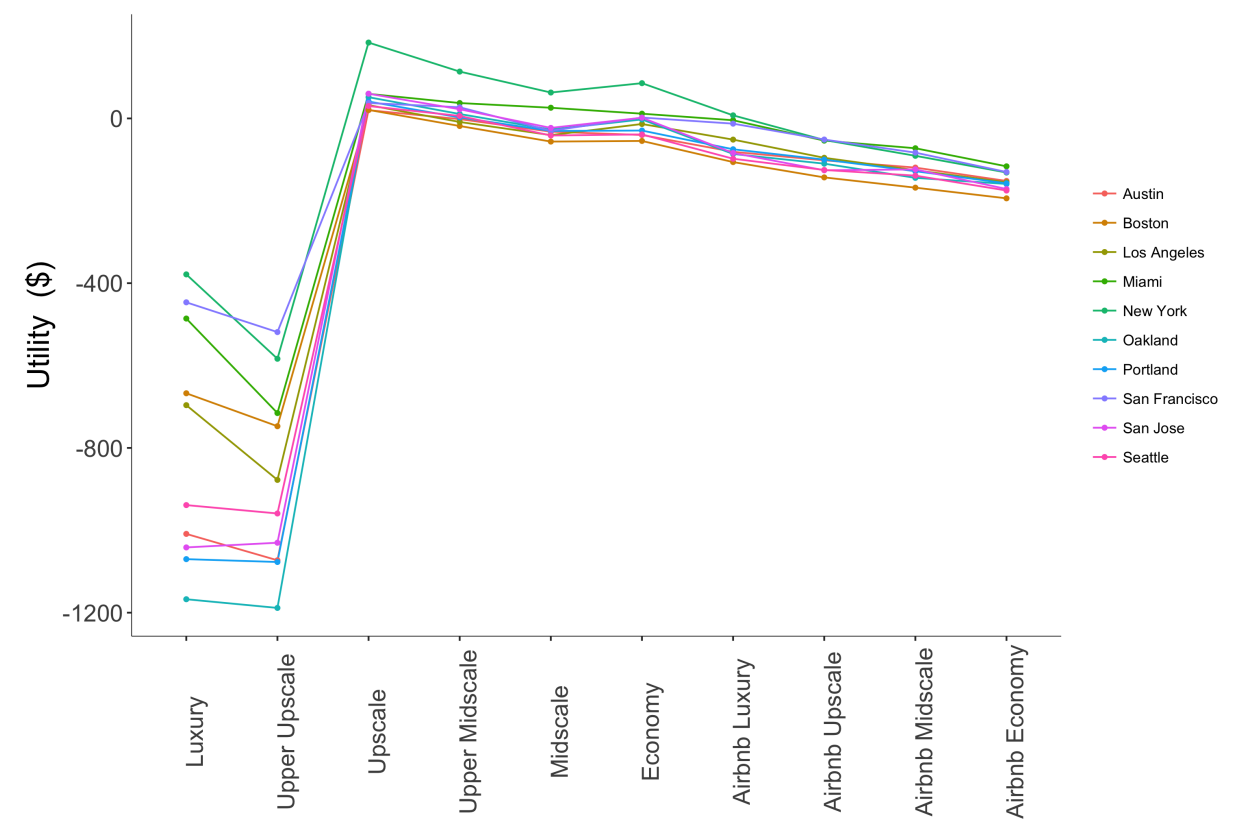

This figure plots the estimated mean utilities for accommodation options across the 10 cities used in our estimation. The values are computed as averages over the last month in our data. The negative values of some of the parameters reflect the fact that our normalization of the outside option means that most people choose the outside option. 
Figure 9: Estimated Hotel Costs

(a) Costs by City - Midscale Hotels

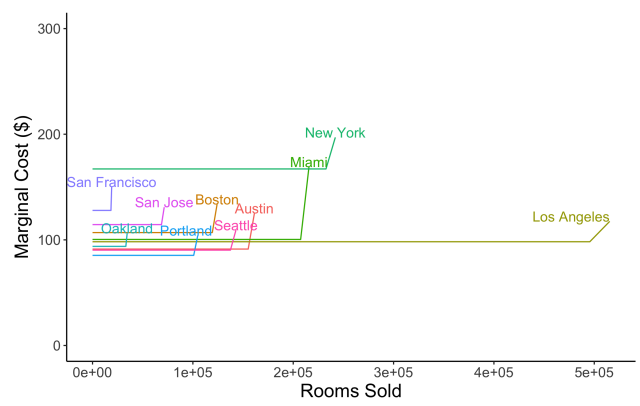

(b) Costs by Hotel Scale - New York City

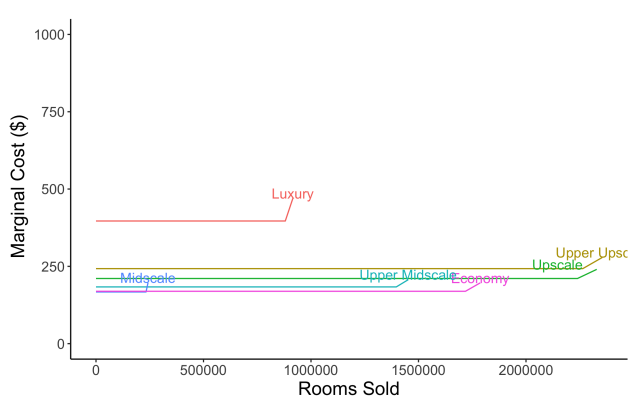

These figures plot the estimated marginal cost curves of hotels across cities (left panel) and across scales (right panel). The values are computed as averages over the last month in our data. Appendix Tables A7 and A8 display the cost estimates by city and hotel scale.

Figure 10: Mean Costs of Airbnb Hosts in New York City

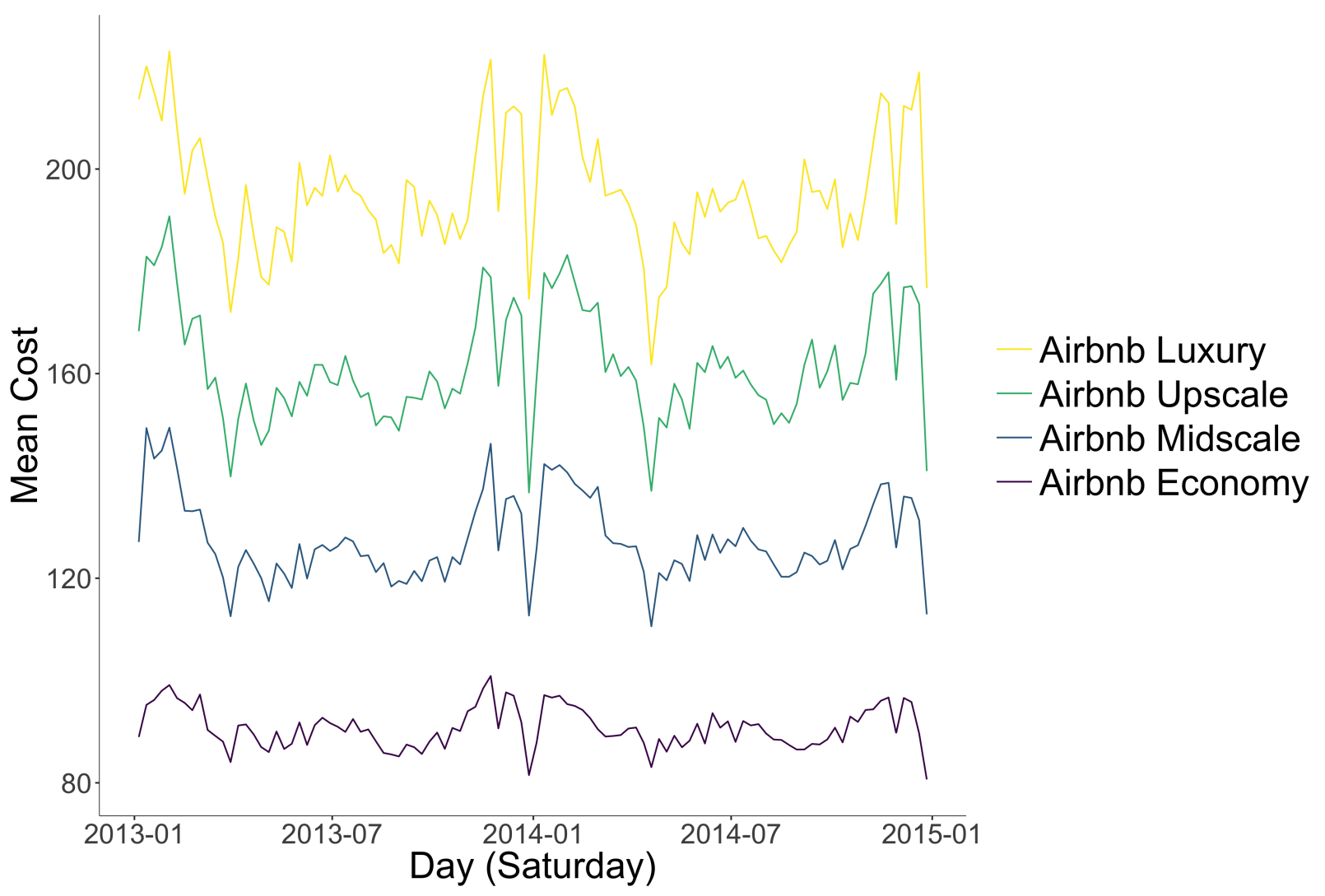

The figures plot the estimated mean costs of Airbnb hosts in New York over time. Appendix Table A9 displays all the estimated means and standard deviations. 


\section{Tables}

Table 1: Descriptive Statistics on Hotel and Airbnb Outcomes

\begin{tabular}{lcccccc}
\hline \hline Statistic & $\mathrm{N}$ & Mean & St. Dev. & Pctl(25) & Median & Pctl(75) \\
\hline Mean Hotel Occupancy & 50 & 0.66 & 0.07 & 0.61 & 0.65 & 0.70 \\
Std Dev Hotel Occupancy & 50 & 0.13 & 0.03 & 0.12 & 0.14 & 0.15 \\
Mean Hotel Price in \$ & 50 & 107.94 & 35.04 & 86.29 & 98.69 & 121.01 \\
Std Dev Hotel Price & 50 & 16.34 & 9.34 & 9.77 & 13.00 & 21.02 \\
Mean Hotel Revenue (Thousand \$) & 50 & $3,785.34$ & $3,588.86$ & $1,575.12$ & $2,488.65$ & $4,856.56$ \\
Airbnb Share of Available Rooms (Q4 2014) & 50 & 0.02 & 0.03 & 0.005 & 0.01 & 0.03 \\
Airbnb Share of Potential Guests (Q4 2014) & 50 & 0.04 & 0.04 & 0.01 & 0.02 & 0.05 \\
Airbnb Share of Housing Units (Q4 2014) & 50 & 0.001 & 0.001 & 0.0002 & 0.0005 & 0.001 \\
Mean Airbnb Occupancy & 50 & 0.15 & 0.06 & 0.11 & 0.13 & 0.18 \\
Std Dev Airbnb Occupancy & 50 & 0.09 & 0.02 & 0.07 & 0.08 & 0.10 \\
Mean Airbnb Price in \$ & 50 & 108.63 & 24.67 & 92.01 & 99.76 & 120.87 \\
Std Dev Airbnb Price & 50 & 31.24 & 13.17 & 21.78 & 28.50 & 34.29 \\
Mean Airbnb to Hotel Price Ratio & 50 & 1.06 & 0.28 & 0.91 & 1.00 & 1.14 \\
Std Dev Price Ratio & 50 & 0.33 & 0.18 & 0.21 & 0.29 & 0.39 \\
\hline
\end{tabular}

This table shows hotel and Airbnb descriptive statistics for the 50 cities in our sample. For each city, we compute the mean and standard deviation of daily occupancy rate and price for hotels and Airbnb listings. The Airbnb share of available rooms is computed as the average of daily share of rooms in the last quarter, i.e. October - December 2014. The Airbnb share of potential guests is computed as the quarterly average of rooms adjusted for their realized capacity, assuming that the typical hotel has the same number of average guests as a 'Midscale' Airbnb listing. This number is larger than the Airbnb share of rooms because Airbnb listings typically have higher capacity than hotel rooms.

Table 2: Descriptive Statistics on Market Characteristics

\begin{tabular}{lcccccc}
\hline \hline Statistic & $\mathrm{N}$ & Mean & St. Dev. & Pctl(25) & Median & Pctl(75) \\
\hline WRLURI & 50 & 0.31 & 0.82 & -0.30 & 0.20 & 0.84 \\
Share of Undevelopable Area & 46 & 0.30 & 0.24 & 0.09 & 0.23 & 0.43 \\
Percent Never Married & 48 & 0.33 & 0.03 & 0.31 & 0.33 & 0.36 \\
Share of Children & 48 & 0.31 & 0.02 & 0.30 & 0.31 & 0.32 \\
Rent to Income Ratio & 50 & 0.18 & 0.03 & 0.15 & 0.17 & 0.20 \\
Std Dev of Google Trend (2011) & 50 & 12.05 & 4.22 & 9.62 & 11.51 & 13.70 \\
Std Dev of Incoming Passengers (2011)/10,000 & 50 & 6.95 & 6.63 & 1.89 & 4.17 & 11.30 \\
Passengers' Growth (2012-2011) & 50 & 0.02 & 0.06 & -0.02 & 0.01 & 0.04 \\
\hline
\end{tabular}

The table shows descriptive statistics on market characteristics for the 50 cities in our sample. The WRLURI and Saiz's share of undevelopable area are proxies for constraints to hotel supply. The share of children and unmarried adults proxy for the availability of Airbnb hosts. The standard deviation of Google trends and incoming passengers are two measures of demand volatility. 
Table 3: City Characteristics and Size of Airbnb

\begin{tabular}{|c|c|c|c|}
\hline & \multicolumn{2}{|c|}{ Airbnb Share of Rooms } & \multirow[b]{2}{*}{$(3)$} \\
\hline & $(1)$ & $(2)$ & \\
\hline Undevelopable Area & $\begin{array}{c}0.025 \\
(0.016)\end{array}$ & $\begin{array}{c}0.021 \\
(0.015)\end{array}$ & $\begin{array}{c}0.013 \\
(0.013)\end{array}$ \\
\hline SD. Incoming Air Passengers (2011) & $\begin{array}{c}0.002^{* * *} \\
(0.001)\end{array}$ & $\begin{array}{c}0.002^{* *} \\
(0.001)\end{array}$ & $\begin{array}{l}0.0003 \\
(0.001)\end{array}$ \\
\hline$\%$ Never Married & $\begin{array}{c}0.364^{* *} \\
(0.140)\end{array}$ & $\begin{array}{c}0.391^{* * *} \\
(0.144)\end{array}$ & $\begin{array}{c}0.214 \\
(0.131)\end{array}$ \\
\hline \% Growth in Air Passengers (2012-2011) & $\begin{array}{c}0.064 \\
(0.058)\end{array}$ & $\begin{array}{c}0.089 \\
(0.058)\end{array}$ & $\begin{array}{c}0.074 \\
(0.050)\end{array}$ \\
\hline Wharton Residential Land Use Index (WRLURI) & & $\begin{array}{c}0.006 \\
(0.004)\end{array}$ & $\begin{array}{c}0.004 \\
(0.003)\end{array}$ \\
\hline \% Children & & $\begin{array}{c}-0.323^{*} \\
(0.177)\end{array}$ & $\begin{array}{l}-0.165 \\
(0.156)\end{array}$ \\
\hline Log(Market Size) & $\begin{array}{l}-0.011 \\
(0.007)\end{array}$ & $\begin{array}{l}-0.007 \\
(0.007)\end{array}$ & $\begin{array}{l}-0.010 \\
(0.006)\end{array}$ \\
\hline Log(Rev. Per Room (2011)) & & & $\begin{array}{c}0.055^{* * *} \\
(0.014)\end{array}$ \\
\hline Constant & $\begin{array}{c}0.001 \\
(0.080)\end{array}$ & $\begin{array}{c}0.051 \\
(0.079)\end{array}$ & $\begin{array}{l}-0.120 \\
(0.081)\end{array}$ \\
\hline Observations & 46 & 46 & 46 \\
\hline $\mathrm{R}^{2}$ & 0.584 & 0.644 & 0.748 \\
\hline
\end{tabular}

This table shows linear regressions of the size of Airbnb on market characteristics linked to supply constraints, demand volatility, and the costs of hosting. The size of Airbnb is the average of daily share of rooms in the last quarter, i.e. October - December 2014. The standard deviation of incoming passengers is divided by 10,000 to make the coefficient comparable to the other variables. Descriptive statistics are shown in Tables 1 and 2. Market size is measured as the average number of rooms available in the last quarter of 2014. 
Table 4: The Supply Elasticity of Hotels and Peer Hosts

\begin{tabular}{lcc}
\hline \hline & Log(Hotel Rooms Boooked) & Log(Airbnb Rooms Booked) \\
& $(1)$ & $(2)$ \\
\hline $\log$ (Hotel Rooms) & $0.538^{* * *}$ & \\
& $(0.188)$ & \\
$\log$ (Hotel Price) & $1.072^{* * *}$ & \\
& $(0.069)$ & $0.622^{* * *}$ \\
$\log$ (Airbnb Rooms) & & $(0.098)$ \\
& & $2.164^{* * *}$ \\
$\log$ (Airbnb Price) & & $(0.296)$ \\
& & \\
\hline IV & & Yes \\
City FE & Yes & Yes \\
Year-Month FE & Yes & Yes \\
Day of Week FE & Yes & Yes \\
Observations & Yes & 250,923 \\
$\mathrm{R}^{2}$ & 268,489 & 0.895 \\
\hline \hline
\end{tabular}

Note: $\quad$ Column 2 includes the log number of residents leaving by air, and the log number of outgoing travel searches on Google as controls.

Standard Errors are clustered at the city and year-month level.

The table shows results of IV regressions of the log of hotel and Airbnb bookings on the corresponding price and room availability. Column 2 includes the log of departing (local) air travelers, and the one week lag of the log of local Google Search Trends for hotels outside of the city as additional controls. The instruments are demand-side shifters - the one week lag of the log of the Google Search Trends and the log of arriving (not returning) flight travelers - in both columns. In column 2 the number of Airbnb available listings is instrumented with city-specific quadratic time trends that capture the diffusion process of the platform. Adding the city-day observations with no Airbnb bookings (and using hotel prices in column 2) does not change the results. Instrumenting for hotel capacity like we do for Airbnb does not change the results either. 
Table 5: Hotel Revenue and the Size of Airbnb

\begin{tabular}{lccc}
\hline \hline & $\log ($ RevPAR $)$ & Occupancy Rate & Log(Price) \\
& $(1)$ & $(2)$ & $(3)$ \\
\hline $\log$ (Incoming Air Passengers) & $1.169^{* * *}$ & $0.394^{* * *}$ & $0.498^{* * *}$ \\
& $(0.065)$ & $(0.041)$ & $(0.041)$ \\
$\log$ (Google Search Trend) & $0.147^{* * *}$ & $0.054^{* * *}$ & $0.069^{* *}$ \\
& $(0.049)$ & $(0.012)$ & $(0.027)$ \\
$\log ($ Hotel Rooms) & $-0.768^{* * *}$ & $-0.436^{* * *}$ & -0.078 \\
& $(0.200)$ & $(0.078)$ & $(0.148)$ \\
$\log$ (Available Listings) & & & $-0.025^{*}$ \\
& $-0.033^{* *}$ & -0.006 & $(0.013)$ \\
\hline IV & $(0.014)$ & $(0.005)$ & Yes \\
City FE & & & Yes \\
Year-Quarter FE & Yes & Yes & Yes \\
Day of Week FE & Yes & Yes & Yes \\
Observations & Yes & Yes & 0.853 \\
$\mathrm{R}^{2}$ & 268,489 & 268,489 & 0.582 \\
\hline \hline Note: & 0.729 & Standard Errors Clustered at a City Level
\end{tabular}

This table shows results of IV estimates of equation 4, where the size of Airbnb is measured as the number of available listings. The Google search trend is a one-week lag. The instruments are city-specific quadratic time trends. The dependent variable is revenue per available room in column 1, occupancy rate in column 2, and price in column 3 . Appendix $B$ discusses the instrumental variables strategy and endogeneity concerns in greater detail. 


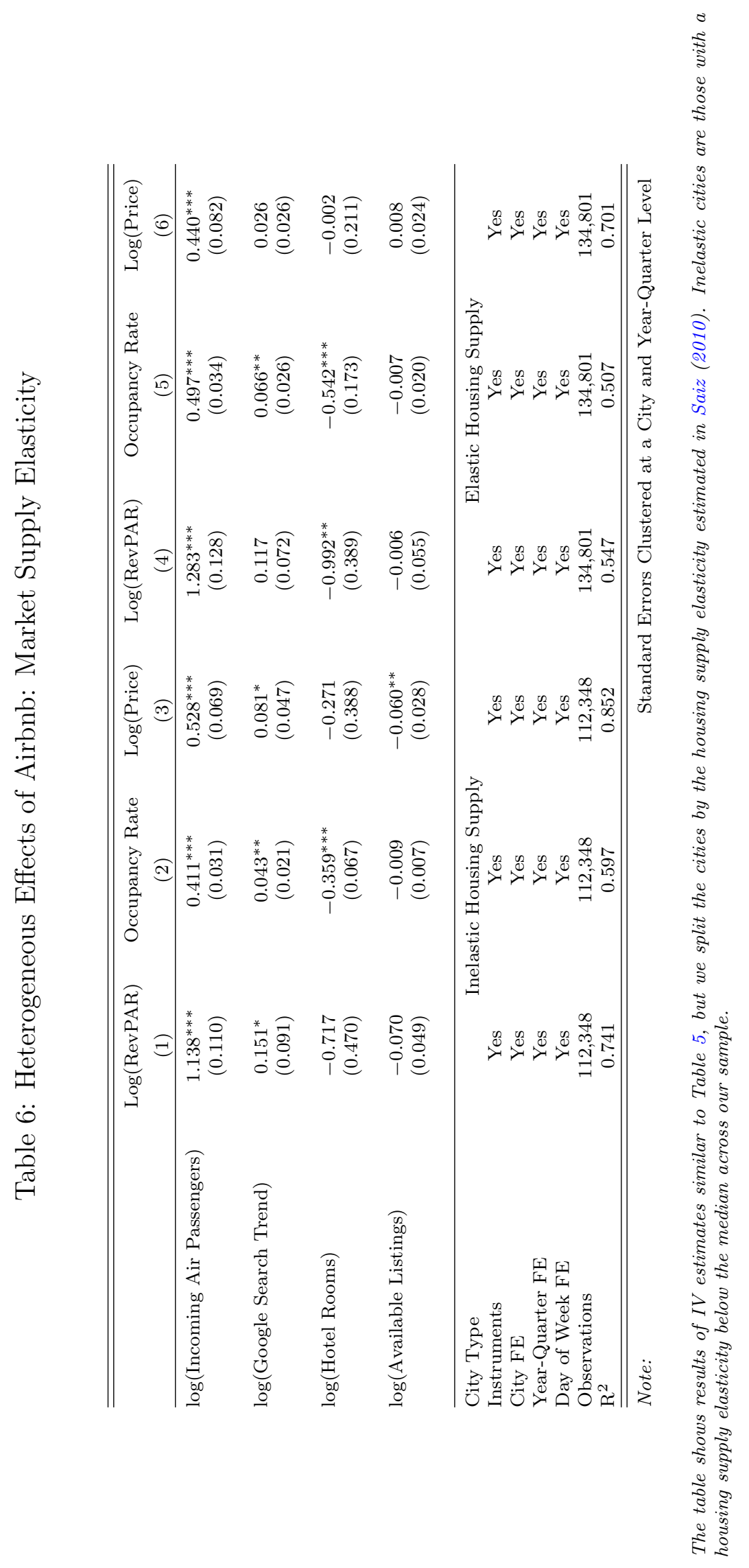




\section{Table 7: Estimates of Selected Demand Parameters}

\begin{tabular}{lrr}
\hline Parameter & Value & Std. Error \\
\hline Price & -0.033 & 0.001 \\
Log Google Trend & 10.500 & 0.026 \\
Log Google Trend Sq. & -0.768 & 0.013 \\
Log Travelers To & 2.386 & 0.065 \\
Log Travelers To Sq. & 0.067 & 0.000 \\
Std. Deviation on Inside Option & 3.753 & 1.106 \\
Std. Deviation on High Scale & 29.762 & 0.005 \\
Std. Deviation on Price & 0.006 & 0.023 \\
\hline
\end{tabular}

This table displays the estimates and standard errors for selected parameters in travelers' utility. High scale includes luxury and upper upscale hotels.

Table 8: Consumer Surplus from Airbnb

\begin{tabular}{lccc}
\hline \multicolumn{1}{c}{ City } & \multicolumn{2}{c}{ Change in CS (MM) } \\
\cline { 1 - 1 } Austin & Unconstrained & Price Adjustment \\
Boston & -5.1 & -9.4 \\
Los Angeles & -6.8 & -13.0 \\
Miami & -25.6 & -41.5 \\
New York & -9.0 & -14.0 \\
Oakland & -56.8 & -126.2 \\
Portland & -3.6 & -6.0 \\
San Francisco & -5.5 & -8.6 \\
San Jose & -21.3 & -41.2 \\
Seattle & -3.6 & -6.2 \\
All & -5.7 & -10.0 \\
All (Compression Nights) & -142.9 & -276.1 \\
All (Non Compression Nights) & -37.4 & -98.8 \\
\hline
\end{tabular}

This table displays the consumer surplus change from two scenarios without Airbnb. "Unconstrained" refers to the counterfactual scenario in which Airbnb options do not exist, hotels do not adjust prices and can accommodate any additional bookings regardless of their actual capacity. In the "Price Adjustment" counterfactual, we let hotels adjust their prices in response to the absence of Airbnb and accounting for capacity constraints. "All" refers to the sum of consumer surplus changes across all cities, and "All (Compression Nights)" refers to the sum across cities for time periods when at least one hotel option in the city has an occupancy rate of 95\% or more. All calculations are for 2014. 
Table 9: Consumer Surplus from Airbnb (per night)

\begin{tabular}{|c|c|c|c|}
\hline \multirow[t]{2}{*}{ City } & \multirow[t]{2}{*}{ Avg. Airbnb Price } & \multicolumn{2}{|c|}{ Consumer Surplus per Person-Night } \\
\hline & & Unconstrained & Price Adjustment \\
\hline Austin & 160.6 & -24.7 & -45.3 \\
\hline Boston & 120.3 & -23.4 & -44.8 \\
\hline Los Angeles & 122.0 & -23.1 & -37.4 \\
\hline Miami & 148.7 & -23.7 & -36.7 \\
\hline New York & 145.3 & -18.9 & -42.1 \\
\hline Oakland & 89.2 & -25.7 & -42.9 \\
\hline Portland & 94.7 & -23.9 & -37.2 \\
\hline San Francisco & 146.0 & -21.2 & -41.1 \\
\hline San Jose & 106.2 & -26.0 & -45.2 \\
\hline Seattle & 108.0 & -26.0 & -45.8 \\
\hline All & 136.2 & -21.3 & -41.1 \\
\hline All (Compression Nights) & 143.6 & -21.4 & -56.5 \\
\hline All (Non Compression Nights) & 133.6 & -21.3 & -35.7 \\
\hline
\end{tabular}

This table displays the consumer surplus loss per room-night without Airbnb. The two counterfactual scenarios - third and fourth columns - are the same as in Table 8. The last three rows are also defined as in Table 8. The second column displays the average transacted price per room-night on Airbnb. All calculations are for 2014.

Table 10: Competitive Effects on Hotels

\begin{tabular}{|c|c|c|c|c|c|c|}
\hline \multirow[t]{2}{*}{ City } & \multicolumn{2}{|c|}{$\%$ Change Quantity } & \multicolumn{2}{|c|}{ \% Change Revenue } & \multicolumn{2}{|c|}{$\%$ Change Profit } \\
\hline & Unconst. & Price Adj. & Unconst. & Price Adj. & Unconst. & Price Adj. \\
\hline Austin & 1.31 & 0.96 & 1.21 & 1.20 & 1.34 & 1.91 \\
\hline Boston & 1.02 & 0.69 & 0.78 & 0.75 & 0.53 & 1.51 \\
\hline Los Angeles & 1.91 & 1.45 & 1.40 & 1.36 & 1.21 & 4.72 \\
\hline Miami & 1.32 & 0.97 & 0.98 & 1.00 & 1.59 & 2.03 \\
\hline New York & 3.64 & 2.00 & 2.94 & 2.24 & 2.95 & 4.99 \\
\hline Oakland & 1.48 & 1.13 & 1.37 & 1.41 & 1.13 & 5.45 \\
\hline Portland & 1.77 & 1.43 & 1.54 & 1.52 & 1.34 & 4.06 \\
\hline San Francisco & 2.65 & 1.55 & 2.00 & 1.68 & 1.66 & 4.31 \\
\hline San Jose & 0.84 & 0.63 & 0.73 & 0.72 & 0.61 & 1.99 \\
\hline Seattle & 1.10 & 0.79 & 0.93 & 0.89 & 0.96 & 2.48 \\
\hline All & 2.05 & 1.32 & 1.81 & 1.54 & 1.89 & 3.69 \\
\hline All (Compression) & 2.45 & 0.99 & 2.16 & 1.73 & 1.95 & 3.21 \\
\hline All (Non Compression) & 1.93 & 1.41 & 1.69 & 1.47 & 1.81 & 4.36 \\
\hline
\end{tabular}

This table displays changes in hotel bookings, revenues, and profits without Airbnb. The two counterfactual scenarios as well as the last three rows are defined as in Table 8. For the profit calculation, we exclude the cost component from Equation 7 that is increasing as quantity approaches capacity. 
Table 11: Airbnb Bookings: Market Expansion versus Business Stealing

\begin{tabular}{lrr}
\hline & \multicolumn{2}{c}{ Share New Bookings } \\
& Unconstr. & Price Adjust. \\
\hline Austin & 0.27 & 0.46 \\
Boston & 0.32 & 0.54 \\
Los Angeles & 0.30 & 0.47 \\
Miami & 0.31 & 0.49 \\
New York & 0.33 & 0.63 \\
Oakland & 0.28 & 0.45 \\
Portland & 0.28 & 0.42 \\
San Francisco & 0.34 & 0.61 \\
San Jose & 0.29 & 0.47 \\
Seattle & 0.29 & 0.49 \\
All & 0.32 & 0.56 \\
All (Constrained) & 0.31 & 0.72 \\
All (Non Constrained) & 0.32 & 0.50 \\
\hline
\end{tabular}

This table shows the share of Airbnb bookings that would not have been hotel bookings in the absence of Airbnb, i.e. the share of Airbnb bookings constituting market expansion. The two counterfactual scenarios are defined as in Table 8.

Table 12: Peer Producer Surplus

\begin{tabular}{lrr}
\hline \multicolumn{1}{c}{ City } & Avg. Peer Surplus per Night & Total Peer Surplus (MM) \\
\hline Austin & 30.22 & 1.15 \\
Boston & 25.29 & 0.93 \\
Los Angeles & 24.71 & 3.14 \\
Miami & 23.45 & 1.06 \\
New York & 25.99 & 7.31 \\
Oakland & 24.35 & 0.48 \\
Portland & 27.33 & 0.91 \\
San Francisco & 26.20 & 2.64 \\
San Jose & 26.10 & 0.49 \\
Seattle & 26.16 & 0.86 \\
All (Compression Nights) & 25.85 & 18.96 \\
All (Co & 8.41 \\
All (Non Compression Nights) & 27.00 & 10.55 \\
\hline
\end{tabular}

This table displays peer producer surplus, per room-night and in the aggregate, for 2014. The two counterfactual scenarios as well as the last three rows are defined as in Table 8. 